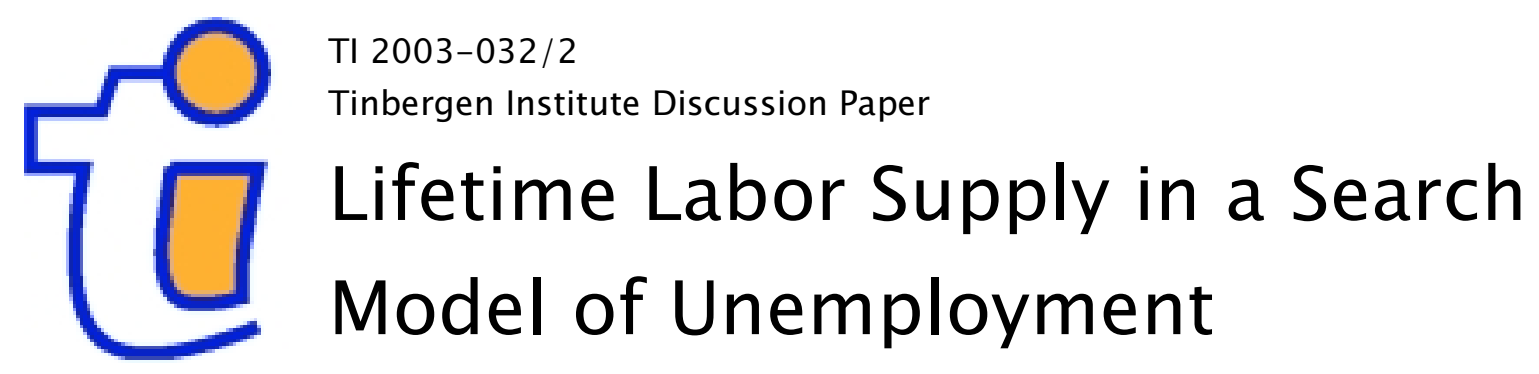

Leon J.H. Bettendorf*

D. Peter Broer

OCFEB, Faculty of Economics, Erasmus University Rotterdam, and CPB Netherlands Bureau of Economic Policy Analysis, The Hague.

* Tinbergen Institute. 


\section{Tinbergen Institute}

The Tinbergen Institute is the institute for economic research of the Erasmus Universiteit Rotterdam, Universiteit van Amsterdam, and Vrije Universiteit Amsterdam.

Tinbergen Institute Amsterdam

Roetersstraat 31

1018 WB Amsterdam

The Netherlands

Tel.: $\quad+31(0) 205513500$

Fax: $\quad+31(0) 205513555$

Tinbergen Institute Rotterdam

Burg. Oudlaan 50

3062 PA Rotterdam

The Netherlands

Tel.: $\quad+31(0) 104088900$

Fax: $\quad+31(0) 104089031$

Please send questions and/or remarks of nonscientific nature to driessen@tinbergen.nl.

Most TI discussion papers can be downloaded at http://www.tinbergen.nl. 


\title{
Lifetime Labor Supply in a Search Model of Unemployment
}

\author{
Leon J.H. Bettendorf, D. Peter Broer* \\ OCFEB, Erasmus University Rotterdam \\ CPB Netherlands Bureau of Economic Policy Analysis, The Hague
}

March 31, 2003

\begin{abstract}
This paper investigates the age-dependency of participation and unemployment by integrating job search with intertemporal optimizing behavior of finitely-lived households. We find that search frictions and tax rates distort the decisions of older workers to a much larger extent than that of young workers. This finding provides an explanation of the observed fall of participation rates of elder workers as a result of the post-war increase in tax rates and replacement rates. We show that the age pattern of search unemployment does not match observed unemployment and we propose a new concept of 'voluntary' unemployment that agrees well with observations.
\end{abstract}

Keywords: search frictions, labor supply, life cycle, unemployment, retirement

JEL codes: J64, D91, J31.

*Address: OCFEB, Faculty of Economics, Erasmus University, P.O. Box 1738, 3000 DR Rotterdam, the Netherlands. Email: bettendorf@few.eur.nl, broer@few.eur.nl. We would like to thank Jaap Abbring, Lans Bovenberg, Harry van Dalen, Ben Heijdra, Albert van der Horst and Ed Westerhout for useful comments on earlier versions of this paper. 


\section{Introduction}

The decline in labor force participation of the elderly is one of the most striking developments of post-war labor markets. The participation ratio has declined strongly in virtually all developed countries over the past few decades. The survey of Gruber and Wise (1997) shows that participation rates for persons in the age bracket 60-64 have fallen by more than half in most countries. This participation rate is now less than $20 \%$ in the Netherlands, and around 50\% in the U.S. This trend stands in sharp contrast to the increase in the overall participation in most countries in the nineties and it suggests that participation rate of the elderly may be affected differently by economic conditions than participation of prime-aged households.

This paper investigates the relation between social insurance, taxes, and labor market participation of elder workers from a life cycle perspective. We explore the interaction between firms and households on the labor market to explain the relation between participation, unemployment, and age. The focus of the paper is on the distortions created by the tax system and social security provisions with respect to participation rates over the life time of a household. To capture the agedependency of labor market participation, the paper links the life cycle model of labor supply and consumption with an imperfect labor market in which search costs create a surplus value for a job match which is divided by wage bargaining. The paper thus integrates life-cycle models of labor supply (see Blundell and MaCurdy (1999)) and the Mortensen-Pissarides (MP) matching model of wage formation and unemployment (Pissarides (1990), Mortensen and Pissarides (1999a)).

In the paper the age dependency of the job value plays a central role in the explanation of the development of participation rates over the life cycle. For a household, the job value is the marginal utility of a job in consumption units. The job value therefore determines the return to search and the search effort. In the MP model, the job value equals the difference between the value of employment and the value of unemployment. Here we use the more general definition introduced by Shi and Wen (1997), which is defined in terms of the marginal utility of leisure.

With finite lives, the job value must eventually fall to zero, at the point in time where the household exits the labor market. This decline of the job value during the later stages of a household's active life forms a key element in our explanation of the observed fall in participation rates. First, a low job value implies a low return to search and a low search effort. Low search intensities imply falling participation rates, as the job creation rate falls below the job destruction rate. This implies that the expected exit date from the labor force affects labor participation several years before. Second, taxes and social insurance shorten the time remaining until the job value falls to zero, as they lower the net return to work. Forward-looking behavior implies that taxes and social insurance have a particularly large impact on the participation of elder workers. Low search intensities of elder households generate participation rates that increasingly fall behind the participation profile that would result in the absence of distortions. Labor taxes and social insurance therefore create a dynamic distortion, in the same way as capital income taxation, because they affect an investment decision, the search effort. We show that the distortionary impact of taxes and 
replacement rates affects in particular labor market participation of elder workers.

The age structure of unemployment also depends on the development of the job value. The decline of job value in the later stages of the life of a household implies that search unemployment of older workers is close to zero in the years preceding labor market exit. This implication of search models does not agree with observed unemployment rates by age. We argue that search models can be reconciled with the observed evidence by modeling unemployment in the same terms in which it is measured. By defining unemployment as the extra amount that people would be willing to work at the going wage rate if a job were offered to them (i.e. without requiring search effort), we show that the model predicts that unemployment actually rises in the years prior to labor market exit. This feature of the model corresponds well with observed age-unemployment statistics.

Another implication of our model is that the relation between wages and productivity varies by age. Positive job values indicate a surplus value of a match. This surplus is divided between employer and worker in proportion to their bargaining power. For middle-aged workers, this implies that the wage is below their marginal product. However, if the value of a job is low, there is little surplus to be divided, and the wage outcome is near the marginal productivity of a worker. Since the value of a job must decline as the worker approaches voluntary retirement, workers that are near voluntary retirement receive approximately their marginal product.

In the literature on labor market search, the effects of heterogeneity by age have received scant attention. The standard model of search unemployment (Pissarides (1990)) does not explicitly integrate job search with intertemporal optimizing behavior of households. The reservation wage equals the return to permanent income in unemployment. Merz (1995) extends the basic model to an intertemporal context to addresses RBC issues. This introduces an explicit relation between the reservation wage and the marginal rate of substitution between leisure and consumption. Heer (1997), Atkinson (1999), and Shi and Wen (1999) apply the model to study the effects of social insurance on employment and welfare.

Models of search unemployment with heterogeneous households are less common. Mortensen and Pissarides (1999b) consider the effects of household heterogeneity by skill level, assuming that labor markets are segmented by skill level. They find that a high level of social insurance affects labor participation of low-skilled households relatively more than that of high-skilled households. The fundamental reason is that both types value leisure equally, whereas the opportunity costs of leisure are lower for low-skilled households. In this paper, we do not assume that the marginal value of leisure is constant among different households. Instead, we distinguish households by age. Bhattacharya et al. (2001) and Shimer and Smith (2001) look at the optimal level of social security in a model with old and young workers. They find that public pensions can serve to compensate for a search externality, by inducing old workers to search less. In comparison with these papers, we do not focus on welfare issues but we look at the effects of social insurance on labor participation in a fully developed life cycle model. 
The remainder of this paper is organized as follows. The model is expounded in Section 2. Section 2.1 discusses the matching model and Section 2.2 discusses the implications of household heterogeneity by age from the side of the firm. Section 2.3 describes labor supply and search decisions for an individual household, and Section 3 discusses the implications for wage formation. Section 4 uses these results to analyze the optimal pattern of labor supply and job search over the life cycle of a household, using a specific parameterization of the utility function. Section 5 investigates the link between search costs, labor taxes, and unemployment. The results of Sections 4 and 5 are checked for the general case by numerical simulation in Section 6. Section 7 offers some conclusions.

\section{The Model}

The labor market is characterized by transactions costs through a search externality. Search takes time and the probability of a match depends on the search effort of the other market party as well. Jobs are infinitely divisible, so that the labor market may be interpreted as a market for hours of work. Jobs are destructed if their value drops to zero. In addition, jobs disappear at an exogenous rate as a result of unspecified turbulence.

Firms hire workers by posting vacancies. For a firm, the value of a match is determined by the present value of the difference between the marginal product of a worker and his wage. Because capital is mobile, the marginal product of a worker depends only on the exogenous interest rate and an age component. The present value is also affected by the expected duration of the match. Workers of different ages have different values for the firm.

Households have finite lives. Productivity is age-related and eventually falls with age. Households choose optimal paths of leisure and consumption over their lifetime. To obtain employment, a household must search for jobs. Search time does not generate utility. All exit options are regarded as equivalent, so that all forms of non-participation receive the same, age-dependent, benefit. For households, there are no job setup costs so the income risk of unemployment can be covered through self-insurance by holding many small jobs. ${ }^{1}$

Job values for households are defined as the value of the utility gain in consumption units of a marginally larger job. Job values depend positively on current and future wage rates and negatively on current and future benefits, on interest rates and on separation rates. The return to search consists of the value of a job times the matching rate per unit of search. If the return to search is lower than the marginal utility of leisure, a household stops searching for new jobs. A separation occurs if the value of a job drops to zero.

\footnotetext{
${ }^{1}$ Alternatively, and equivalently, it may be assumed that the unemployment risk is insured through income pooling within an extended family with an infinite number of members. See e.g. Merz (1995).
} 


\subsection{Labor Market Flows}

Let $U$ denote the effective number of job seekers and $V$ the number of vacancies. The number of contacts between job seekers and vacancies is given by the matching function

$$
M=x(U, V)
$$

Equation (1) describes the number of job matches in the labor market. It is assumed that $x$ is homogeneous of degree one. Denote the aggregate vacancy-job seeker ratio by $\theta, \theta=V / U$. The contact rate per vacancy is now $M / V=x\left(\theta^{-1}, 1\right)$. This contact rate is beyond the control of the individual firm.

It is assumed that the probability of a contact between a worker of a specific age and a firm is independent of age and depends only on the aggregate contact rate and the proportion of jobseeking workers of that age. Let the proportion of job-seeking workers of generation $t_{0}$ at time $t$ be denoted by $\bar{u}\left(t, t_{0}\right)=U\left(t, t_{0}\right) / U(t)$, then the inflow rate into employment of generation $t_{0}$ is

$$
m\left(t, t_{0}\right)=\frac{M\left(t, t_{0}\right)}{V(t)}=x\left(\theta^{-1}(t), 1\right) \bar{u}\left(t, t_{0}\right)
$$

Denote the separation rate of workers of generation $t_{0}$ by $s\left(t, t_{0}\right)$, then the change in employment per generation is

$$
\dot{N}\left(t, t_{0}\right)=m\left(t, t_{0}\right) V(t)-s\left(t, t_{0}\right) N\left(t, t_{0}\right)
$$

where $N\left(t, t_{0}\right)$ denotes the work force by generation.

\subsection{Firms}

The state vector for an individual firm $i$ at $t$ contains the employment vector $N_{i}\left(t, t_{0}\right)$ and the capital stock $K_{i}(t)$. It is assumed that depreciation is exponential, so that

$$
\dot{K}_{i}(t)=I_{i}(t)-\delta K_{i}(t)
$$

where $\delta$ the deterioration rate of capital. The employment equation is analogous to (3),

$$
\dot{N}_{i}\left(t, t_{0}\right)=m\left(t, t_{0}\right) V_{i}(t)-s\left(t, t_{0}\right) N_{i}\left(t, t_{0}\right)
$$

It is assumed that a firm can freely dismiss workers. This implies that it can choose the separation rate $s$, subject to an exogenous quit rate: $s\left(t, t_{0}\right) \geq \bar{q}\left(t, t_{0}\right)$. The production function is $F\left[K_{i}, N_{i}\right]$, where

$$
N_{i}(t)=\int_{-\infty}^{t} h(t-\tau) N_{i}(t, \tau) \mathrm{d} \tau
$$

where $h(\tau)$ gives the productivity index of a worker of age $\tau$. This specification posits that workers of different age groups are perfectly substitutable in production. The market value $\Pi_{i}$ of an individual firm is determined by the arbitrage condition

$$
r(t) \Pi_{i}(t)=F\left[K_{i}(t), N_{i}(t)\right]-\int_{-\infty}^{t} w(t, \tau) N_{i}(t, \tau) \mathrm{d} \tau-\gamma_{0}(t) V_{i}(t)-p_{I}(t) I_{i}(t)+\dot{\Pi}_{i}(t)
$$


where $w$ is the wage rate and $\gamma_{0}$ denotes the cost of opening a vacancy.

The marginal productivity relation for capital satisfies the standard condition

$$
F_{K}\left[K_{i}(t), N_{i}(t)\right]=p_{I}(t)\left(r(t)+\delta-\frac{\dot{p}_{I}(t)}{p_{I}(t)}\right)
$$

Since the hiring of workers is subject to transaction costs, workers, like capital, are an asset to the firm. The asset value $\phi_{N}$ of a worker is given by the following arbitrage relation

$$
r(t) \phi_{N_{i}}\left(t, t_{0}\right)=\dot{\phi}_{N_{i}}\left(t, t_{0}\right)+F_{N}\left[K_{i}(t), N_{i}(t)\right] h\left(t-t_{0}\right)-w\left(t, t_{0}\right)-s\left(t, t_{0}\right) \phi_{N_{i}}\left(t, t_{0}\right)
$$

The return to hiring a new worker, $r \phi_{N}$, must equal the capital gain, $\dot{\phi}_{N}$, plus the increase in production and minus the extra wage costs and the depreciation of the work force due to separations. A voluntary separation occurs at a point $T\left(t_{0}\right)$ where $\phi_{N_{i}}\left(T, t_{0}\right)=0, F_{N} h\left(T-t_{0}\right)-w\left(T, t_{0}\right)=0$, and $\dot{\phi}_{N}<0$. That is, the labor contract ends if and when the asset value of the worker turns negative (the dismissal condition). ${ }^{2}$ Because of the transactions costs of hiring workers, the wage is not in general equal to the marginal product of a worker. (8) suggests that the marginal productivity of labor may be either higher or lower than the wage rate, depending on the user cost of workers (net of wage costs), $\phi_{N}\left(r+s-\dot{\phi}_{N} / \phi_{N}\right)$.

Vacancies are not age-specific, because the return to a worker of any age is nonnegative, due to the age-specificity of wages. ${ }^{3}$ Opening of a vacancy therefore results in job applicants of all ages. The total value of the resulting matches must equal the cost of opening the vacancy:

$$
\int_{-\infty}^{t} \phi_{N_{i}}(t, \tau) m(t, \tau) \mathrm{d} \tau=\gamma_{0}(t)
$$

(9) is a generalization of the free-entry condition for unfilled jobs in Pissarides (1990). It is more general in that the return to opening a vacancy depends on the age composition of the job applicants and the effect of age on the value of a worker.

\subsection{Households}

Household maximize their lifetime utility over consumption and leisure, subject to a time constraint, a budget constraint, and a transactions constraint on the labor market. Time is divided between working $n$, leisure $l$, and job search $u$ :

$$
u\left(t, t_{0}\right)+n\left(t, t_{0}\right)+l\left(t, t_{0}\right)=1
$$

where $t$ is the time index and $t_{0}$ denotes the generation index of the household. $u\left(t, t_{0}\right)$ is equal to the time spent searching for jobs and does not directly generate utility. It is assumed that on-thejob search is impossible. $u$ may therefore be interpreted as search unemployment. The transactions

\footnotetext{
${ }^{2}$ If $\phi_{N}=0$ and $\dot{\phi}_{N}=0$, continuation of the job does not affect the market value of firm.

${ }^{3}$ The determination of wages is discussed in Section 3.
} 
technology on the labor market is given by (1). Households initially enter the labor market without a job, $n\left(t_{0}, t_{0}\right)=0$. For the individual household, the inflow into employment is

$$
\dot{n}\left(t, t_{0}\right)=\chi(t) u\left(t, t_{0}\right)-q\left(t, t_{0}\right) n\left(t, t_{0}\right)
$$

where $\chi(t)=M\left(t, t_{0}\right) / U\left(t, t_{0}\right)=\theta(t) x\left(\theta^{-1}(t), 1\right)$ is the matching rate for job searchers. Note that the matching rate per hour of search is the same for all generations, because the matching technology (1) does not depend on age. The separation rate $q\left(t, t_{0}\right)$ is bounded below by the exogenous job destruction rate $\bar{q}\left(t, t_{0}\right)$, i.e. $q\left(t, t_{0}\right) \geq \bar{q}\left(t, t_{0}\right) .{ }^{4}$ Voluntary quits occur if $q>\bar{q}$. An individual household may reduce its employment suddenly by a finite amount by choosing an unbounded quit rate.

Households face two kinds of uncertainty, that are both fully diversified. The first is the income uncertainty associated with variations in employment level. In the absence of indivisibilities, a household can self-insure against job loss by filling several jobs, each for a small fraction of the available time. ${ }^{5}$ With an infinite amount of infinitesimal jobs per household, this reduces income uncertainty to zero. The second source of uncertainty is the death hazard. It is assumed that this uncertainty is diversified by letting each household receive an annuity from a life insurance company in return for bequeathing it its remaining assets upon its decease (Yaari (1965)). Let $\Lambda(\tau)$ denote the survival probability of a new-born household till age $\tau$. Then the mortality rate is $\mu\left(t, t_{0}\right)=-\dot{\Lambda}\left(t-t_{0}\right) / \Lambda\left(t-t_{0}\right)$, and the annuity is $\mu\left(t, t_{0}\right) a\left(t, t_{0}\right)$.

The budget constraint of a member of generation $t_{0}$ is

$$
\begin{aligned}
\dot{a}\left(t, t_{0}\right) & =\left(r(t)+\mu\left(t, t_{0}\right)\right) a\left(t, t_{0}\right)+w\left(t, t_{0}\right) n\left(t, t_{0}\right)-T\left(w\left(t, t_{0}\right) n\left(t, t_{0}\right)\right) \\
& +\pi_{u}\left(t, t_{0}\right) u\left(t, t_{0}\right)+z\left(t, t_{0}\right)\left(1-n\left(t, t_{0}\right)\right)-\left(1+\tau_{c}(t)\right) c\left(t, t_{0}\right) \\
z\left(t, t_{0}\right) & =b\left(t, t_{0}\right) w\left(t, t_{0}\right)
\end{aligned}
$$

where $a\left(t, t_{0}\right)$ denotes the asset holdings of a member of generation $t_{0}$, with $a\left(t_{0}, t_{0}\right)=0, T\left(w\left(t, t_{0}\right) n\left(t, t_{0}\right)\right)$ is the tax schedule for labor income, $\tau_{c}$ denotes the consumption tax, $z\left(t, t_{0}\right)$ is the (age-dependent) unemployment benefit rate, and $b\left(t, t_{0}\right)$ is the replacement rate. The unemployment benefit is based on wage income of the average worker of a given age. It is therefore out of control for the individual worker. ${ }^{6} \pi_{u}$ denotes the search premium on job search of the social security agency. ${ }^{7}$ Note

\footnotetext{
${ }^{4}$ Note that the separation rate $q$ for the individual household is different from the separation rate for the firm, $s$, on account of population dynamics, see Section 3, eq. (22).

${ }^{5}$ Self-employed people, with many customers, and consultants in business firms are common examples of this type of insurance. Alternatively, it may be assumed that households of the same age, who face the same unemployment risk, are engaged in income pooling. Of course, this assumption generates a moral hazard problem unless the households can be regarded as members of an extended family.

${ }^{6}$ This assumption reflects the rules pertaining to welfare benefits in the Netherlands. Unemployment insurance is typically linked to the current wage level, if with a maximum, and only for a finite amount of time.

${ }^{7}$ Equivalently, $w\left(t, t_{0}\right) b\left(t, t_{0}\right)+\pi_{u}(t)$ may be interpreted as the unemployment benefit, in which case $\pi_{u}(t)$ is a penalty for not searching.
} 
that the observed number of matches in (11) may provide the information needed by the social security agency to identify $u\left(t, t_{0}\right)$ separately from leisure. This information is used in (12), where it is assumed that the social security agency can monitor the time spent searching.

The utility functional is

$$
\Upsilon\left(t, t_{0}\right)=\frac{1}{1-1 / \gamma} \int_{t}^{t_{0}+T} \mathrm{e}^{-\rho(\tau-t)} \frac{\Lambda\left(\tau-t_{0}\right)}{\Lambda\left(t-t_{0}\right)} v\left(c\left(\tau, t_{0}\right), l\left(\tau, t_{0}\right)\right)^{1-1 / \gamma} \mathrm{d} \tau
$$

where $T$ denotes the maximum life of a household, defined by $T=\inf \{\tau \mid \Lambda(\tau)=0\}$. It is assumed that $T<\infty$. The decision problem of the household extends the standard life cycle consumption-saving framework in that there is a second investment margin present. A household has to decide whether to sacrifice leisure by searching for jobs. The return to this investment contains an age-specific component, both because of finite lives and because of the relation between age and productivity that is present in the wage profile $w\left(t, t_{0}\right)$. As the household grows older, it will generally enter into a disinvestment phase by reducing its work effort and search intensity. In this respect the problem is similar to the human capital accumulation problem. A difference is that search generates jobs, whereas schooling generates a higher return to jobs (for a survey of human capital models, see Weiss (1986)).

\subsubsection{Job Value and Labor Supply}

The household maximizes utility (14) subject to the employment constraint (11), the budget constraint (12), and restrictions on the use of time in (10). The savings-consumption decision is described by the Keynes-Ramsey rule

$$
\begin{aligned}
& \dot{\lambda}_{a}\left(\tau, t_{0}\right)=-\lambda_{a}\left(\tau, t_{0}\right)\left(r(\tau)+\mu\left(\tau, t_{0}\right)\right) \\
& \lambda_{a}\left(\tau, t_{0}\right)=\mathrm{e}^{-\rho(\tau-t)} \frac{\Lambda\left(\tau-t_{0}\right)}{\Lambda\left(t-t_{0}\right)} v\left(\tau, t_{0}\right)^{-1 / \gamma} \frac{v_{c}\left(c\left(\tau, t_{0}\right), l\left(\tau, t_{0}\right)\right)}{1+\tau_{c}(\tau)}
\end{aligned}
$$

where $\lambda_{a}=\frac{\partial \Upsilon}{\partial a}$ is the marginal utility of financial wealth.

To discuss the allocation of time it is useful to introduce the job value $p_{n}$, defined by

$$
p_{n}\left(t, t_{0}\right)=\frac{\partial \Upsilon\left(t, t_{0}\right)}{\partial n\left(t, t_{0}\right)} / \frac{\partial \Upsilon\left(t, t_{0}\right)}{\partial a\left(t, t_{0}\right)}
$$

The job value gives the marginal utility of a job, measured in terms of the marginal utility of wealth. The job value satisfies the following arbitrage equation

$$
\begin{aligned}
& w\left(\tau, t_{0}\right)\left[1-T^{\prime}\left(w\left(\tau, t_{0}\right) n\left(\tau, t_{0}\right)\right)\right]+\dot{p}_{n}\left(\tau, t_{0}\right)-q\left(\tau, t_{0}\right) p_{n}\left(\tau, t_{0}\right)+\lambda_{n}\left(\tau, t_{0}\right) \\
& =\left(1+\tau_{c}(\tau)\right) \frac{v_{l}\left(t, t_{0}\right)}{v_{c}\left(t, t_{0}\right)}+z\left(\tau, t_{0}\right)+\left(r(\tau)+\mu\left(\tau, t_{0}\right)\right) p_{n}\left(\tau, t_{0}\right)
\end{aligned}
$$

where the time derivative is wrt. $\tau$. This equation compares the return to a job on the left-hand side with the alternate return of leisure, $\left(1+\tau_{c}\right) v_{l} / v_{c}+z$, plus the return on tangible assets, $(r+\mu) p_{n}$, 
on the right-hand side. $\lambda_{n}$ is a Kuhn-Tucker multiplier for the nonnegativity constraint on employment $(n \geq 0)$. All use of time is necessarily nonnegative, and the Kuhn-Tucker conditions are given by

$$
\begin{aligned}
\lambda_{u}\left(\tau, t_{0}\right) u\left(\tau, t_{0}\right) & =0 \\
\lambda_{n}\left(\tau, t_{0}\right) n\left(\tau, t_{0}\right) & =0 \\
\lambda_{l}\left(\tau, t_{0}\right) l\left(\tau, t_{0}\right) & =0
\end{aligned}
$$

The possible combinations of the values of these multipliers determine the phases of the life cycle of the household, as summarized in Proposition 1 below. We shall assume $a$ priori that the curvature of the utility function ensures that $l>0$, so that $\lambda_{l}=0$ identically.

Time allocation decisions are described by

$$
\begin{aligned}
\frac{v_{l}\left(c\left(\tau, t_{0}\right), l\left(\tau, t_{0}\right)\right)}{v_{c}\left(c\left(\tau, t_{0}\right), l\left(\tau, t_{0}\right)\right)} & =\left(\chi(\tau) p_{n}\left(\tau, t_{0}\right)+\pi_{u}\left(\tau, t_{0}\right)+\lambda_{u}\left(\tau, t_{0}\right)\right) /\left(1+\tau_{c}(\tau)\right) \\
\lambda_{q}\left(\tau, t_{0}\right) & =p_{n}\left(\tau, t_{0}\right) n\left(\tau, t_{0}\right) \\
0 & =\lambda_{q}\left(\tau, t_{0}\right)\left(q\left(\tau, t_{0}\right)-\bar{q}\left(\tau, t_{0}\right)\right)
\end{aligned}
$$

(18a) compares the marginal utility of leisure with that of financial wealth. If the household is actively searching, $\lambda_{u}=0$ so that the opportunity costs of leisure equal the return to search. However, if the return to search is sufficiently low, the household may stop searching for a job and the marginal value of leisure exceeds the return on the labor market. Note that this case does not arise in the Pissarides (1990) model, as it cannot be an equilibrium with a single representative household. With heterogeneity by age the link between value of leisure and returns on the labor market may be cut for part of the life of a household. (18b) demands that voluntary quits are zero if the job value is positive, where $(18 \mathrm{c})$ represents the complementary slackness condition of the job separation restriction $q\left(t, t_{0}\right) \geq \bar{q}\left(t, t_{0}\right)$.

It is proved in Appendix $C$ that the decisions of the household can be classified as belonging to one of four phases, depending on the possible combinations of the Kuhn-Tucker multipliers:

Proposition 1 Let $\pi_{u}<\left(1-b-T^{\prime}\right) w$. Then labor supply behavior of a household falls in one of four different stages

1. Searching for new jobs. The marginal value of jobs is positive ( $p_{n}>0, \lambda_{u}=0, \lambda_{q}>0$, $\left.\lambda_{n}=0\right)$

2. Employed, not searching for new jobs, but not voluntarily quitting either. The marginal job value is positive $\left(p_{n}>0, \lambda_{u}>0, \lambda_{q}>0, \lambda_{n}=0\right)$

3. Lowering its participation at a pace greater than the job destruction rate. The marginal job value is zero $\left(p_{n}=0, \lambda_{u}>0, \lambda_{q}=0, \lambda_{n}=0\right)$ 
4. Retired or without a job and not searching. The job value is zero ( $p_{n}=0, \lambda_{u}>0, \lambda_{q}=0$, $\left.\lambda_{n}>0\right)$

Stage 1 generally corresponds to the period in which the household is young and its prospects on the labor market are improving. This case is characterized by active searching for new job opportunities, i.e. $u\left(t, t_{0}\right)>0$ and no voluntary quits $q\left(t, t_{0}\right)=\bar{q}\left(t, t_{0}\right)$. By (18b), this implies a positive job value over time, $p_{n}\left(t, t_{0}\right)>0$. Eventually, the job value will start to decline, both on account of the finite horizon of the household and on account of the declining labor productivity, and we enter the second stage.

Stage 1 is the only case considered in the standard Mortensen-Pissarides job search model. To see that the formulation of the standard model is equivalent to the one used in the present paper, combine (18a) and (16) to obtain the dynamic job value equation for actively searching households

$$
\begin{aligned}
& \dot{p}_{n}\left(\tau, t_{0}\right)+w\left(\tau, t_{0}\right)\left[1-T^{\prime}\left(w\left(\tau, t_{0}\right) n\left(\tau, t_{0}\right)\right)\right] \\
& =z\left(\tau, t_{0}\right)+\pi_{u}\left(\tau, t_{0}\right)+\left(r(\tau)+\mu\left(\tau, t_{0}\right)+\chi(\tau)+q\left(\tau, t_{0}\right)\right) p_{n}\left(\tau, t_{0}\right)
\end{aligned}
$$

This equation is equivalent to (3.23) in Pissarides (1990), with $p_{n}$ corresponding to $E-U$. However, (19) is not valid if the household does not search, but still attaches a positive value to the jobs that it fills.

Stage 2 corresponds to a situation in which the value of a job is still positive, $p_{n}\left(t, t_{0}\right)>0$, but too low to induce the household to look for new jobs, i.e. $u\left(t, t_{0}\right)=0$. It follows from (18b) and (18c) that $q\left(t, t_{0}\right)=\bar{q}\left(t, t_{0}\right)$, i.e. no voluntary quits. Hence the change in labor supply of the household is given by (11) as $\dot{n}\left(t, t_{0}\right)=-\bar{q}\left(t, t_{0}\right) n\left(t, t_{0}\right)$. In this stage, the opportunity costs of search are larger than the expected benefits, so that (19) does not hold (but (16) does). This may happen e.g. because the outflow rate $\chi$ from unemployment is small (a discouraged worker effect), or because the value of a job is small, either as a result of a high replacement rate, or in view of the approaching retirement date.

Stage 3 is characterized by zero search $(u=0)$ and voluntary reductions in labor participation $(q>\bar{q})$. This case ensues once the household wants to reduce its work effort at a faster pace than is compatible with the exogenous job destruction rate $\bar{q}$. During this phase

$$
\frac{v_{l}\left(t, t_{0}\right)}{v_{c}\left(t, t_{0}\right)}=\left(w\left(\tau, t_{0}\right)\left[1-T^{\prime}\left(w\left(\tau, t_{0}\right) n\left(\tau, t_{0}\right)\right)\right]-z\left(\tau, t_{0}\right)\right) /\left(1+\tau_{c}(\tau)\right)
$$

so that with voluntary quitting, the opportunity costs of leisure equal the net after-tax wage rate. During this phase household labor supply therefore conforms to the classical static labor supply schedule.

The development of the job value over the working life of a household can be written in terms of the discounted value of the future gains from employment. Denote $\mathscr{T}_{h}\left(t, t_{0}\right)=\left\{\tau \geq t \mid \lambda_{n}\left(\tau, t_{0}\right)=0\right\}$ 
and integrate (16) to obtain

$$
\begin{aligned}
p_{n}\left(t, t_{0}\right)= & \int_{\mathscr{T}_{h}\left(t, t_{0}\right)}\left(w\left(\tau, t_{0}\right)\left[1-T^{\prime}\left(w\left(\tau, t_{0}\right) n\left(\tau, t_{0}\right)\right)\right]-z\left(\tau, t_{0}\right)-\left(1+\tau_{c}(\tau)\right) \frac{v_{l}\left(\tau, t_{0}\right)}{v_{c}\left(\tau, t_{0}\right)}\right) \\
& \cdot \exp \left[-\int_{t}^{\tau}\left(q\left(u, t_{0}\right)+r(u)+\mu\left(u, t_{0}\right)\right) \mathrm{d} u\right] \mathrm{d} \tau
\end{aligned}
$$

This equation holds irrespective of whether the household searches or quits. In the integrand $z+\left(1+\tau_{c}\right) v_{l} / v_{c}$ defines the fall-back position of the household in terms of the alternate income from unemployment plus the monetary value of leisure. Marginal labor income is discounted at the applicable interest rate for households of generation $t_{0}$, plus the labor market turnover rate $q$. Note that the job value depends on the marginal labor tax rate, because bargaining is effectively over hours. In contrast to static models of the labor market, the net wage does not necessarily exceed the fall-back position of households in all periods. Note however that it follows from (16) that if the integrand is negative at time $\tau \in \mathscr{T}_{h}$, the job value must be increasing at time $\tau$. Intuitively, a low current wage may be compensated for by high expected future wages.

The final phase is retirement from the labor force, characterized by $l\left(t, t_{0}\right)=1, u\left(t, t_{0}\right)=0$, and $n\left(t, t_{0}\right)=0$. The job value is zero as well, so that (16) results in

$$
\frac{v_{l}\left(t, t_{0}\right)}{v_{c}\left(t, t_{0}\right)}>\left(w\left(\tau, t_{0}\right)\left[1-T^{\prime}\left(w\left(\tau, t_{0}\right) n\left(\tau, t_{0}\right)\right)\right]-z\left(\tau, t_{0}\right)\right) /\left(1+\tau_{c}(\tau)\right)
$$

These four stages exhaust the possible optimal choices of the household. What remains open is whether they occur in the particular order in which they have been presented. Outside the steady state, this is not necessarily the case. A household may decide to temporarily stop looking for jobs if the prospect of finding new ones is particularly bad during a recession, or it may wish to temporarily withdraw from the labor market if (after-tax) wages are particularly low.

\section{Wage Formation}

Labor market equilibrium requires that supply and demand balance for workers of each generation

$$
N\left(t, t_{0}\right)=n\left(t, t_{0}\right) \operatorname{gen}\left(t_{0}\right) \Lambda\left(t-t_{0}\right)
$$

where $g \operatorname{en}\left(t_{0}\right)$ denotes the initial size of generation $t_{0}$. Hence, $\dot{N} / N=\dot{n} / n-\mu$. This implies that the market separation rate equals the individual separation rate plus the mortality rate

$$
s\left(t, t_{0}\right)=q\left(t, t_{0}\right)+\mu\left(t, t_{0}\right)
$$

It is assumed that the market clearing wage is set by bargaining between job seekers and firms to divide the surplus value of the match. The value of a match for the firm is given by $\phi_{N}\left(t, t_{0}\right)$ in (8), and for the worker by $p_{n}\left(t, t_{0}\right)$ in (16). We assume that commitment over future wages is impossible, so that implicit contracts, as in Lazear (1979), cannot occur. The subgame perfect 
Nash solution therefore satisfies $w\left(t, t_{0}\right)=\underset{w\left(t, t_{0}\right)}{\arg \max } p_{n}\left(t, t_{0}\right)^{\omega} \phi_{N}\left(t, t_{0}\right)^{1-\omega}$, where $0<\omega<1$ is the relative bargaining strength of the household. Using the expressions for the job values (8) and (16), the Nash solution results in the well-known sharing rule

$$
\left[1-\varepsilon_{T} T^{\prime}\right] \omega \phi_{N}\left(t, t_{0}\right)=(1-\omega) p_{n}\left(t, t_{0}\right)
$$

where $\varepsilon_{T}$ is defined in terms of the elasticity of the marginal tax function, $\varepsilon_{T}=1+x T^{\prime \prime}(x) / T^{\prime}(x)$. Note that $\varepsilon_{T}=1$ iff the marginal labor tax is independent of income.

For a linear tax system (23) yields

$$
w\left(t, t_{0}\right)=\omega F_{N}(t) h\left(t-t_{0}\right)+\frac{1-\omega}{1-T^{\prime}}\left[\left(1+\tau_{c}(t)\right) \frac{v_{l}\left(t, t_{0}\right)}{v_{c}\left(t, t_{0}\right)}+b\left(t, t_{0}\right) w\left(t, t_{0}\right)\right]
$$

(24) shows that the wage outcome rises with productivity $F_{N} h$, the replacement ratio $b$, the marginal $\operatorname{tax} T^{\prime}$, consumption taxes $\tau_{c}$, and the value of leisure $v_{l} / v_{c}$. If the household is actively searching, (18a) shows that the wage equals

$$
w\left(t, t_{0}\right)=\omega F_{N}(t) h\left(t-t_{0}\right)+\frac{1-\omega}{1-T^{\prime}}\left[\chi p_{n}\left(t, t_{0}\right)+\pi_{u}\left(t, t_{0}\right)+b\left(t, t_{0}\right) w\left(t, t_{0}\right)\right]
$$

The fall-back position of the household consists of the return to search, $\chi p_{n}+\pi_{u}$, plus the unemployment benefit. If the household is quitting voluntarily $\left(q\left(t, t_{0}\right)>\bar{q}\left(t, t_{0}\right)\right)$, using (20) shows that

$$
w\left(t, t_{0}\right)=F_{N}(t) h\left(t-t_{0}\right)
$$

That is, if a household is reducing its work effort, and therefore attaches zero value to a job, the wage outcome for its remaining employment equals its marginal productivity. We summarize these findings in

Proposition 2 Let the wage tax be a linear function of wage income. Then the wage rate follows from (24). For actively searching households this is equivalent to (25) and for households with a zero job value the wage equals the marginal productivity as given in (26).

\section{Labor Supply and Unemployment over the Life Cycle}

In this section we study the time profile of labor supply and search effort over the life cycle of an individual household. The time profiles of both consumption and leisure depend to a large extent on the size of the intertemporal elasticity of substitution (IES) for leisure and for consumption. There is substantial uncertainty about the size of the IES for consumption (see Browning et al. (1999), table 3.1 and 3.2), but the generally accepted view is that it is non-negligible. As for leisure, there is a fair amount of controversy on the empirical relevance of intertemporal substitution for labor supply behavior. The established view, as represented in the surveys of Pencavel (1986) and Card (1994), is that the IES for leisure is small and possibly zero. More recently, 
counter evidence has been found, see Blundell et al. (1993) and Mulligan (1998), so the issue is still unsettled.

We specifically investigate the implications of a zero IES for the supply of labor over the life cycle. The assumption of a zero IES implies that labor supply is not affected by the level of consumption or the level of financial wealth, but depends solely on the (expected) return to labor and job search. This is somewhat restrictive, but the neglect of income effects does allow for an analytic treatment of the problem, so it may be regarded as a useful first step. In addition, we assume that households have a fixed life, so that the death hazard is zero until the full life span has passed. The tax function is assumed to be linear, and the job destruction rate $\bar{q}$ and match rate $\chi$ are constant. In addition, it is assumed that unemployment benefits $b$ and search subsidies $\pi_{u}$ are independent of age. The only remaining age dependency is this section is therefore the productivity of the household, $h(\tau)$. In Section 6 we shall extend our insights to the general case by means of numerical simulation.

\subsection{Labor Supply}

Mankiw et al. (1985) consider a class of utility functions that includes different degrees of substitution for consumption and leisure. If in (14) the flow utility function is of the form ${ }^{8}$

$$
v(c, l)=c+\alpha_{0}^{1 / \alpha_{1}} l^{1-1 / \alpha_{1}} /\left(1-1 / \alpha_{1}\right)
$$

the intertemporal elasticity of substitution of leisure is zero. Using this specification, the first-order conditions can be simplified considerably. Using the job value notation we find as a special case of (15b) and (18a)

$$
\begin{aligned}
\mathrm{e}^{-\rho(\tau-t)} v(\tau)^{-1 / \gamma} & =\lambda_{a}(\tau)\left(1+\tau_{c}\right) \\
\alpha_{0}^{1 / \alpha_{1}} l(\tau)^{-1 / \alpha_{1}} & =\left(\chi p_{n}(\tau)+\pi_{u}+\lambda_{u}(\tau)\right) /\left(1+\tau_{c}\right)
\end{aligned}
$$

Note that the labor supply and search decisions are effectively independent of the marginal utility of wealth, $\lambda_{a}$. This implies that the decisions are recursive: first the life cycle path of labor supply is determined and then consumption. Using this separation property, we first investigate the life cycle path of employment and job search. To simplify the analysis, it will be assumed that the tax function is linear in labor income, so that the marginal tax does not vary over the life cycle. Proposition 1 above distinguishes four different stages within the life cycle, that yield the following equations for the special case under consideration

Stage 1 (search unemployment)

This regime holds if for given $n(\tau)>0$ and $p_{n}(\tau)>0$, the optimal leisure choice in (31c) does not violate the time constraint, i.e. if

$$
\alpha_{0}\left(\left(\chi p_{n}(\tau)+\pi_{u}\right) /\left(1+\tau_{c}\right)\right)^{-\alpha_{1}}<1-n(\tau)
$$

\footnotetext{
${ }^{8}$ In this section the time index refers only to age. We assume that all tax rates and contribution rates are constant.
} 
Because the marginal job has a surplus value for both the employee and the employer, the wage bargain results in a division of the marginal value of (labor) time for the employer and the marginal value of (search) time for the household.

$$
\begin{aligned}
\dot{n}(\tau) & =-\bar{q} n(\tau)+\chi u(\tau) \\
\dot{p}_{n}(\tau) & =-\left(1-T^{\prime}-b\right) w(\tau)+\pi_{u}+(\bar{q}+\chi+r) p_{n}(\tau) \\
l(\tau) & =\alpha_{0}\left(\frac{\chi p_{n}(\tau)+\pi_{u}}{1+\tau_{c}}\right)^{-\alpha_{1}} \\
u(\tau) & =1-n(\tau)-l(\tau) \geq 0 \\
w(\tau) & =\left[\omega F_{N} h(\tau)+\frac{1-\omega}{1-T^{\prime}}\left(\chi p_{n}(\tau)+\pi_{u}\right)\right] /\left(1-(1-\omega) \frac{b}{1-T^{\prime}}\right)
\end{aligned}
$$

Substituting from (31c)-(31e), the differential equation system is therefore

$$
\begin{aligned}
\dot{n}(\tau) & =-(\bar{q}+\chi) n(\tau)+\chi\left(1-\alpha_{0}\left(\frac{\chi p_{n}(\tau)+\pi_{u}}{1+\tau_{c}}\right)^{-\alpha_{1}}\right) \\
\dot{p}_{n}(\tau) & =-\frac{\omega\left(1-T^{\prime}\right)}{1-T^{\prime}-(1-\omega) b}\left(\left(1-T^{\prime}-b\right) F_{N} h(\tau)-\pi_{u}\right) \\
& +\left(\bar{q}+r+\frac{\omega\left(1-T^{\prime}\right) \chi}{1-T^{\prime}-(1-\omega) b}\right) p_{n}(\tau)
\end{aligned}
$$

This differential equation system is non-autonomous. It has constant coefficients, but the first term in the $\dot{p}_{n}$ equation is time-dependent on account of the age dependency of the productivity of the household. Note that the $\dot{p}_{n}=0$ line is a straight line in the $\left(n, p_{n}\right)$ plane:

$$
p_{n}(\tau)=\frac{\omega\left(1-T^{\prime}\right)}{1-T^{\prime}-(1-\omega) b} \frac{\left(1-T^{\prime}-b\right) F_{N} h(\tau)-\pi_{u}}{\bar{q}+r+\frac{\omega\left(1-T^{\prime}\right) \chi}{1-T^{\prime}-(1-\omega) b}}
$$

The $\dot{p}_{n}=0$ line shifts up with the productivity of the household. The $\dot{n}=0$ line is given by

$$
n=\frac{\chi}{\chi+\bar{q}}\left(1-\alpha_{0}\left(\frac{\chi p_{n}+\pi_{u}}{1+\tau_{c}}\right)^{-\alpha_{1}}\right)
$$

Comparing (35) with (30), we see that all points $\left(n, p_{n}\right)$ on the $\dot{n}=0$ curve satisfy $u>0$. In addition, the $\dot{n}=0$ line is increasing and concave in $p_{n}$.

\section{Stage 2 (zero search)}

This regime applies if, for given $n(\tau)$ and $p_{n}(\tau)$, the solution to (31c) yields a violation of the time constraint (31d). The set of periods for which the household is in Phase 2 is therefore given by

$$
\left\{\tau \mid n(\tau)+\alpha_{0}\left(\frac{\chi p_{n}(\tau)+\pi_{u}}{1+\tau_{c}}\right)^{-\alpha_{1}}>1, p_{n}(\tau)>0\right\}
$$

If the household has stopped searching, employment falls at the exogenous separation rate $\bar{q}$. The employment level determines leisure via (37c). The value of time for the household is now larger 
than the marginal revenue of search, so that the bargained wage explicitly depends on the marginal utility of leisure (37e).

$$
\begin{aligned}
\dot{n}(\tau) & =-\bar{q} n(\tau) \\
\dot{p}_{n}(\tau) & =-\left(1-T^{\prime}-b\right) w(\tau)+\left(1+\tau_{c}\right)\left(\frac{1-n(\tau)}{\alpha_{0}}\right)^{-1 / \alpha_{1}}+(\bar{q}+r) p_{n}(\tau) \\
l(\tau) & =1-n(\tau) \\
u(\tau) & =0 \\
w(\tau) & =\left[\omega F_{N} h(\tau)+(1-\omega) \frac{1+\tau_{c}}{1-T^{\prime}}\left[\frac{1-n(\tau)}{\alpha_{0}}\right]^{-1 / \alpha_{1}}\right] /\left(1-(1-\omega) \frac{b}{1-T^{\prime}}\right)
\end{aligned}
$$

Note that the $\dot{n}=0$ line coincides with the $p_{n}$-axis. The differential equation for $p_{n}$ is given by

$$
\begin{aligned}
\dot{p}_{n}(\tau) & =-\frac{\left(1-T^{\prime}-b\right)}{1-T^{\prime}-(1-\omega) b} \omega\left(1-T^{\prime}\right) F_{N} h(\tau)+(\bar{q}+r) p_{n}(\tau) \\
& +\frac{\omega\left(1-T^{\prime}\right)\left(1+\tau_{c}\right)}{1-T^{\prime}-(1-\omega) b}\left[\frac{1-n(\tau)}{\alpha_{0}}\right]^{-1 / \alpha_{1}}
\end{aligned}
$$

The $\dot{p}_{n}=0$ line for this stage may therefore be written as

$$
p_{n}=\omega\left(1-T^{\prime}\right) \frac{\left(1-T^{\prime}-b\right) F_{N} h(\tau)-\left(1+\tau_{c}\right)\left(\frac{1-n}{\alpha_{0}}\right)^{-1 / \alpha_{1}}}{\left(1-T^{\prime}-(1-\omega) b\right)(\bar{q}+r)}
$$

This equation is decreasing and concave in $n$.

\section{Stage 3 (quitting)}

This phase arises when the household attaches zero value to a marginal job $\left(p_{n}=0\right)$, so that voluntary quits may occur $(q>\bar{q})$. Proposition 1 states that in this case job search is zero, $u(\tau)=0$ and $\lambda_{u}(\tau)>0$. Applying Proposition 2 now yields $w(\tau)=F_{N} h(\tau)$. That is, as the opportunity cost of leisure is just the net wage, the optimal amount of labor supply is determined by the classical labor supply schedule.

$$
\begin{aligned}
\dot{n}(\tau) & =-q(\tau) n(\tau) \\
p_{n}(\tau) & =0 \\
l(\tau) & =\alpha_{0}\left[\frac{1-T^{\prime}-b}{1+\tau_{c}} w(\tau)\right]^{-\alpha_{1}} \\
n(\tau) & =1-l(\tau) \\
w(\tau) & =F_{N} h(\tau)
\end{aligned}
$$

Since $\dot{n}(\tau) / n(\tau) \leq-\bar{q}(\tau)$ during this stage, it follows from (40d) and (40e) that $\dot{h}(\tau) / h(\tau) \leq$ $-\bar{q}(\tau) / \alpha_{1} \cdot n(\tau) / l(\tau)$. That is, quitting is more likely to occur when the participation rate is already low as labor supply elasticities are higher. 
Stage 4 (retirement)

Full retirement $(l=1)$ occurs if the restriction $n \geq 0$ is binding in (40d), i.e. if $\frac{1-T^{\prime}-b}{1+\tau_{c}} w(\tau) \leq \alpha_{0}^{1 / \alpha_{1}}$ or

$$
h(\tau)<\alpha_{0}^{1 / \alpha_{1}}\left(1+\tau_{c}\right) /\left(\left(1-T^{\prime}-b\right) F_{N}\right)
$$

\subsection{Phase Diagram Analysis}

The different stages in life cycle behavior that may apply to the household can be grouped together in a phase diagram. To handle the age-dependent character of productivity, we assume that productivity remains constant until age $T_{1}$, after which it drops to zero. This effectively implies that the household retires at time $T_{1}$. The analysis in Section 4.1 shows that for $\tau<T_{1}$, the flow diagram is given by Figure $1 .{ }^{9}$ The retirement of the household at $\tau=T_{1}$ implies an endpoint condition $n\left(T_{1}\right)=0$. To get there, $n$ must jump at time $\tau=T_{1}$, because the job dynamics in (37a) do not allow the origin to be reached in finite time. Jumping in $n$ implies voluntary quits, so that the job value must be zero just before the household retires. That is, the optimal trajectory in the $\left(n, p_{n}\right)$ plane lands somewhere on the positive $n$-axis, to the left of the $\dot{p}_{n}=0$ line in Figure 1. To find the first part of the trajectory, it is sufficient to observe that the initial job value cannot be above the $\dot{p}_{n}=0$ line, as the resulting trajectory would violate the endpoint conditions. Hence the job value must fall continuously. Labor participation increases during the first phase of the life cycle, until the trajectory intersects the $\dot{n}=0$ line. After that, the household continues to search, but at a reduced intensity, until the trajectory intersects with the $u=0$ line. This moment defines the transition from Phase 1 to Phase 2 in terms of Proposition 1. Both labor participation and the job value continue to fall until the latter is zero. This moment marks the transition to Phase 3. During Phase 3, labor participation depends only on the net wage (see (40c)), and as long as this remains constant participation is constant as well. By assumption, at time $\tau=T_{1}$ productivity drops below the threshold, at which point the household quits its remaining jobs.

We summarize these findings in the following

Proposition 3 Let the period utility function be specified as in (27), and suppose that the productivity profile is constant till retirement and let the household enter the labor market at a zero level of employment. Then the following successive stages may be distinguished ${ }^{10}$

la Labor participation increases, but job value falls. Job search is positive.

$1 b$ Job value and labor participation decrease. Job search is positive.

2 Job value and labor participation decrease. Job search is zero.

\footnotetext{
${ }^{9}$ It is assumed that $\pi_{u}=0$.

${ }^{10}$ The numbering of these stages corresponds to those in Proposition 1 and the numbering of the different parts of the optimal trajectory in Figure 1.
} 
3 Job value is zero. The wage rate is equal to marginal productivity. Labor participation depends only on the after-tax wage rate.

4 The households exits the labor market if its productivity drops below a threshold given in (41).

\section{Search Costs and Unemployment}

\subsection{Search Costs and Implicit Taxes}

In the Mortensen-Pissarides model households do not succeed in obtaining a job costlessly, but first have to invest in search time. This search cost creates a wedge, or implicit tax, between the marginal utility of leisure and the wage rate. The size of this wedge is age-dependent, as elder workers have a shorter horizon than young workers. In this section we investigate the size of the wedge created by search costs in relation to the age of the worker. In general, such a measure contains both an intratemporal substitution effect and an intertemporal substitution effect. As workers prefer to search in periods where the current wage is low and the future wage is high, the size of the total distortion depends partly on the expected time path of wages.

The measure that we apply here does not take into account intertemporal distortions. It compares the marginal utility of leisure with the value that would obtain if the search costs in that period were zero, provided that the income effects of this change are compensated. ${ }^{11}$ Suppose that for a household in period $t$ expected search time $1 / \chi$ suddenly and unexpectedly drops to zero for the time interval $(t, t+\varepsilon)$, after which it returns to its previous level. It follows from (18a) that the job value is zero over this interval. Denote the volumes of consumption of goods and leisure of a household of age $\tau$ that go with zero search costs by $\bar{c}(\tau)$ and $\bar{l}(\tau)$, respectively. ${ }^{12}$ Then the search arbitrage equation (16) simplifies to

$$
\frac{v_{\bar{l}}(\bar{c}(\tau), \bar{l}(\tau))}{v_{\bar{c}}(\bar{c}(\tau), \bar{l}(\tau))}=\frac{w(\tau)\left[1-T^{\prime}(w(\tau) n(\tau))\right]-z(\tau)+\lambda_{n}(\tau)}{1+\tau_{c}}, t<\tau<t+\varepsilon
$$

Note that (42) defines the classical labor supply curve. The income effect of the change in search costs is compensated, so that the marginal utility of wealth $\left(\lambda_{a}\right)$ does not change. It follows from (15b) that for compensated changes

$$
v(\bar{c}(\tau), \bar{l}(\tau))^{-1 / \gamma} v_{\bar{c}}(\bar{c}(\tau), \bar{l}(\tau))=v(c(\tau), l(\tau))^{-1 / \gamma} v_{c}(c(\tau), l(\tau))
$$

In the presence of search costs, the money value of leisure is given as before by (18a)

$$
\frac{v_{l}(c(\tau), l(\tau))}{v_{c}(c(\tau), l(\tau))}=\left(\chi(\tau) p_{n}(\tau)+\pi_{u}+\lambda_{u}(\tau)\right) /\left(1+\tau_{c}\right)
$$

\footnotetext{
${ }^{11}$ The compensation is negative, and approximately equal to the job value times the resulting change in the level of employment.

${ }^{12}$ The analysis in this section is for a given generation. For notational convenience, we assume $t_{0}=0$, so that the generation index can be omitted.
} 
The net search costs equal the value of the leisure foregone, $p_{u}(\tau) \doteq v_{\bar{l}} / v_{\bar{c}}-v_{l} / v_{c}$, so

$$
p_{u}(\tau)=\frac{\left(1-b-T^{\prime}(\tau)\right) w(\tau)+\lambda_{n}(\tau)-\left(\chi(\tau) p_{n}(\tau)+\pi_{u}+\lambda_{u}(\tau)\right)}{1+\tau_{c}}
$$

The search wedge is defined as $\Lambda_{u} \doteq p_{u} /\left(v_{\bar{l}} / v_{\bar{c}}\right)$, so

$$
\Lambda_{u}(\tau)=1-\frac{\chi(\tau) p_{n}(\tau)+\pi_{u}+\lambda_{u}(\tau)}{\left(1-T^{\prime}(\tau)-b\right) w(\tau)+\lambda_{n}(\tau)}
$$

(45) summarizes the effect of search frictions on labor supply in terms of a wedge between Walrasian and actual marginal utility of leisure. Search frictions push the return to job search, $\chi p_{n}+\pi_{u}$, below the after-tax market wage $\left(1-T^{\prime}-b\right) w$. The opportunity costs of leisure may be even lower if the household does not engage in labor market search $\left(\lambda_{u}>0\right)$. On the other hand, it follows from (16) and (18a) that for a household that is fully retired, $\lambda_{u}+\pi_{u}=\left(1-T^{\prime}-b\right) w+\lambda_{n}$, so that $\Lambda_{u}=0$. Combining (44) and (45) yields a relation between search costs and wedges:

$$
p_{u}(\tau)=\left(1-\Lambda_{\tau}(\tau)\right) \Lambda_{u}(\tau) w(\tau)
$$

where $\Lambda_{\tau}=1-\frac{1-T^{\prime}}{1+\tau_{c}}+\frac{b}{1+\tau_{c}}$ denotes the combined effect of the tax wedge and the replacement rate (for $\lambda_{n}=0$ ). That is, after-tax search costs depend positively on the search wedge and negatively on the tax wedge and the replacement rate.

An alternative characterization of search costs may be given by considering the holding cost of a job. Using (16), (44) implies that net search costs are equal to

$$
p_{u}=\frac{1}{1+\tau_{c}} p_{n}\left(r+\bar{q}+\mu-\dot{p}_{n} / p_{n}\right)
$$

This expression relates the net search costs to the implicit capital cost of holding a job. A higher rate of interest implies that the required return to search time increases, so that search cost increase as well. Higher separation rates or higher mortality rates affect the return to job search in a similar fashion. Search costs are lower if the job value is expected to increase, e.g. due to expected wage increases, or if consumption taxes are higher, as a result of lower opportunity costs of leisure.

To find the total size of distortions on the labor market, the marginal value of leisure should be compared with the value of leisure in the absence of any leisure-consumption distortions. Let $l^{*}$ and $c^{*}$ denote the undistorted choices of leisure and consumption, so that $v_{l^{*}} / v_{c^{*}}=w .{ }^{13}$ The total costs of leisure foregone are then $v_{l^{*}} / v_{c^{*}}-v_{l} / v_{c}$, and we may define the labor market wedge as $\Lambda_{l} \doteq 1-\left(v_{l} / v_{c}\right) /\left(v_{l^{*}} / v_{c^{*}}\right)$. The labor market wedge is related to the tax wedge and the search wedge by

$$
\Lambda_{l}=1-\left(1-\Lambda_{\tau}\right)\left(1-\Lambda_{u}\right)
$$

In a life cycle context, it is the total wedge that determines labor market participation. As will appear from the simulation results in Section 6, the tax wedge is generally several times larger than the search wedge. However, as will appear in the next section, the search wedge derives its importance from its effect on search efforts

\footnotetext{
${ }^{13}$ Again, to maintain comparability, the removal of the distortion is accompanied by a compensating transfer.
} 


\subsection{Unemployment}

The theoretical analysis of Section 2.3.1 shows that search effort $u(\tau)$ goes to zero during the later stages of the working life. The model therefore predicts that search unemployment of elder workers is lower than that of young workers. Prima facie, this prediction is at variance with empirical evidence about age-related unemployment rates. For workers below age sixty, observed unemployment rises with age (Rein and Jacobs (1993)). On the other hand, the prediction of the model is consistent with an observed increase in unemployment duration for elder workers.

The standard definition of unemployment is the extent to which people are available for work at the current wage rate. ${ }^{14}$ This definition therefore compares the existing employment of a household with the amount of labor the household would want to supply if a job were offered to them, i.e. in the absence of transactions costs. Interpreted this way, unemployment is a consequence of a non-zero search wedge, as expounded in Section 5.1. We may quantify this concept of unemployment by comparing the amount of leisure in states with and without transactions costs. To neutralize the income effects of the change in transaction costs, we consider a compensated change with constant marginal utility of money. This way we capture not only search unemployment in our unemployment definition but the full size of the distortion generated by transaction costs. In fact, the only difference between the concepts of "unemployment" and "search costs" is the unit of measurement, labor time vs. money. This leads us to define unemployment as

Definition 1 Let $\tau$ denote the age of a household. The level of unemployment of the household is defined as $l(\tau)-\bar{l}(\tau)$, where $\bar{l}(\tau)$ denotes the amount of leisure defined in (42) and (43).

Note that, as defined, unemployment is entirely voluntary. Households rationally choose not to invest in the search time necessary to increase their employment level. However, the definition does connect with the old concept of "involuntary unemployment" in the sense that e.g. elder workers with low participation rates would be willing to work more at the going wage rate. Indeed, the analysis in Section 4.2 shows that the job value is still positive during the larger part of the zero search stage of a household, implying that the reservation wage during that period is below the market wage. It is in this sense that we can say that the level of unemployment is positive for elder workers, even though they do not search for jobs.

\section{Policy Simulations}

To investigate the effect of social insurance benefits and taxes on labor market participation and unemployment over the life cycle of a household in the general case we resort to numerical simulation. To solve the model, we use a discrete-time version, that is described in Appendix A. The

\footnotetext{
${ }^{14}$ The standard OECD definition is that people are unemployed if they are available for work, and have taken steps to obtain work in the last four weeks. The amount of effort invested in job search may be arbitrarily small, however, and in any case a nominal search effort is required to be eligible for unemployment benefits.
} 
Table 1: Tax rates and replacement rates

\begin{tabular}{rrrrr}
\hline \hline$\%$ & $\tau_{k}$ & $\tau_{n}$ & $\tau_{c}$ & $b$ \\
\hline $\mathrm{NL}$ & 24.7 & 41.0 & 18.7 & 51 \\
$\mathrm{US}$ & 31.3 & 22.6 & 6.1 & 14 \\
\hline \hline
\end{tabular}

Source $\tau$ : Carey et al. (2000, Table 4)

$b$ : OECD (2002, Table 3.11).

calibration of the model is described in Appendix B. As a benchmark we use the tax rates and social insurance replacement rates of the Netherlands as they apply to a modal household. To assess the impact of these rates on life cycle behavior of this household, we compare the outcomes with those that would result if the same household were to face the tax and social insurance rates that apply in the U.S. Both sets of rates are presented in Table 1. To separate the effects of changes in the tax system from those of the replacement rate, we execute the transition in two steps, by first changing the replacement rate and then the tax rates.

In addition, we look at the effect of the Dutch rates on low-productivity households with the same preferences and life expectancy as the modal household. In the Netherlands, in contrast to the U.S., the replacement rate is income-dependent and is substantially higher for low-income households. As a result, the effect of the social insurance system on low-productivity households is very different from that of high productivity households. We also looked at the effects of the U.S. system on a low-productivity household. It appeared that for the U.S., productivity hardly matters for labor participation, as the replacement rate is virtually the same, and the marginal value of leisure is therefore proportional to the net wage rate. ${ }^{15}$

In the simulations, the budgetary effects of changes in the taxes and replacement rates are balanced by means of lump-sum taxes and transfers to households. We also take into account the effect of different values of the tax rates and replacement rates on the outcome of wage bargaining. However, we keep the matching rates constant at the initial benchmark value. This way we are able to see the impact of the social security system on life cycle labor supply without the effects of shifts in equilibrium unemployment and vacancies on unemployment duration. These general equilibrium effects change the return to search and thereby tend to obscure the primary effect of taxes and replacement rates on life cycle behavior. At the same time, our neglect of the equilibrium unemployment effects restricts the validity of the welfare effects of the social insurance changes investigated.

We investigate the impact of reforms on the behavior of a young household, who can still adjust her full lifecycle path of labor supply and consumption. Our simulation results do not therefore cover the behavior of elder households, who face an unexpected change in social security. Together with the assumed constancy of matching rates, this implies that the simulation results do not shed

\footnotetext{
${ }^{15}$ This feature of our model contrasts with the Mortensen-Pissarides (1999) model. The difference derives from the specification of leisure in the utility function.
} 
light on the transition path following a reform.

\subsection{Results}

The curves labelled Base in Figures 3-4 represent the time allocation in the base case. Even though the utility function is different, we observe that the household passes through the same four successive stages that are described in Proposition 1. During the first stage, ranging till the age of 54 years, labor supply and search time are strictly positive. In the beginning of active working life, search time is used to increase labor market participation. In the middle of the first stage search effort is fairly constant, and mainly used to compensate for the (exogenous) destruction of jobs. Towards the end of stage I, search time, and consequently labor supply, is reduced. Stage II lasts from 55 to 60 years. During this stage workers no longer search for new jobs. This accelerates the fall of labor participation. At the age of 61 workers start to quit voluntarily (stage III). At the age of 63 they fully retire.

Figure 6 shows the ratio between marginal productivity and the gross wage as a function of age. Firms are willing to pay a wage above marginal productivity for very young workers since they expect that the productivity of these workers will increase rapidly. This creates a capital gain effect in the worker value (see (8)). ${ }^{16}$ The job value rises gradually until age 53 (Figure 5). During this phase, the match surplus is fairly constant as a percentage of marginal productivity, c.q. the marginal value of leisure. This outcome is a consequence of the constancy of the search effort during this phase (Figure 4). From age 53 onwards the job value starts to decline, to reach zero at age 61 . The slowdown in the growth of the job value initially implies that the gap between the wage and marginal productivity widens. ${ }^{17}$ Intuitively, the anticipation of the decline of the job value in the near future lowers the return to search and thereby worsens the bargaining position of the worker. ${ }^{18}$ As the job value continues to fall, the match surplus gradually disappears and labor market exit becomes a viable outside option. When the job value is zero and workers start exiting (Phase III), the wage equals the marginal product (see Proposition 2).

As a first step in the assessment of the effects of taxes and unemployment benefits we look at the size of the distortion by age. The total size of the labor market distortion depends on the labor market wedge (48). However, the age-specific part of this wedge is given by the search wedge, defined in (45), which is presented in Figure 7. This part of the wedge is negative for the first two years, as a result of the capital gain effect (see also (47)). The search wedge is fairly constant between $4 \%$ and $6 \%$ during the middle period of working life. This reflects the transaction costs of the search imperfection, as implied by the transition rates on the labor market (see Appendix

\footnotetext{
${ }^{16}$ Similarly, young workers are prepared to accept a wage below their marginal value of leisure, also to capture the capital gain associated with rising productivity.

${ }^{17}$ Note that this effect works in a direction opposite of implicit contract theory (Lazear (1979)).

${ }^{18}$ The fall-back consists of the unemployment benefits plus the opportunity costs of leisure. These costs fall if the return to search falls.
} 
B). The search wedge then strongly increases around the age at which the job value is maximal, because the imminent decline of the job value lowers the return to search. The increase in the search wedge raises the labor market wedge by a few points and effectively stops job search. Search frictions thus distort the labor supply of older workers to a much larger extent than that of young workers.

The age-specific size of labor market distortions is also illustrated by the age profile of "voluntary' unemployment in Figure 8 (see also Section 5.2). Unemployment is higher for young and elderly workers. Whereas for young workers this mostly reflects a start-up cost, for old workers the age pattern of unemployment reflects the low return to search. A comparison of Figures 4 and 8 clearly shows that the development of search unemployment fails to explain the observed pattern of unemployment by age. A search unemployment-based measure of unemployment predicts that unemployment gradually falls with rising age and is zero from about age 54. On the other hand, the measure that we propose predicts that unemployment is maximal around age 55, and then falls rapidly to zero as workers retire. This corresponds well with observed age-unemployment patterns.

We now turn to the effects of the tax and social security system on labor supply. Table 1 and Figure 2 show that the tax wedge as well as the replacement rate in the U.S. are much lower than in the Netherlands. In a what-if scenario, labelled Low, we simulate the consequences of implementing the US tax and benefit structure in an otherwise unchanged setting. The reform is implemented in two steps, to show the effects of each measure in isolation. The reforms are executed in a budgetary neutral fashion for the government and social insurance funds combined. This way we hope to shed light both on the causes of differences in labor market participation between the Netherlands (or the EC) and the U.S., and on the determinants of the shifts in labor market participation of elder workers generally.

The welfare effects of the reform are substantial, with an equivalent variation of $14 \%$ of lifetime wealth. ${ }^{19}$ This reflects the reduction of the labor market wedge, both on account of the reduction in the replacement rate and the reduction in consumption and labor taxes. The slight increase in the capital income tax does not undo these positive effects. The reform has an accompanying (positive) lump-sum transfer of only $3 \%$ of lifetime wealth. This positive budgetary effect results mainly from the broadening of the labor tax base. Of course, this positive welfare effect springs at least partly from our neglect of a fundamental reason for the existence of social insurance, risk aversion. ${ }^{20}$

As a consequence of the reform, the return to search triples, and participation increases at all

\footnotetext{
${ }^{19}$ In the case of labor market frictions part of the time endowment has to be spend on searching in every period. We therefore define lifetime income as the maximum income that a person aged 19 can attain by combining working and searching time (i.e., without leisure consumption).

${ }^{20}$ However, Costain (1997) and Engen and Gruber (2001) argue that public insurance programmes crowd out saving. Self-insurance of households through precautionary saving may undo much of the positive effects of public insurance.
} 
ages. The effective retirement age moves up by four years (see Figures 3-4). The increase in the return to search is primarily due to a decrease in the tax and replacement rate wedges. Figure 7 shows that the search wedge remains unaffected during most of the working life. However, the increase in search returns shifts the peak of the search wedge to a higher age. This shows that the age-related increase in labor market distortions shifts to higher ages as well. For most age groups, unemployment is virtually the same after the reform, but the age-dependent peak shifts to higher ages (Figure 8). After the reform, unemployed workers in the age group 59-63 do not exit from the labor force (even though they have stopped searching). Wage formation is also affected by the reform. The increase in job value implies that the return to search and the marginal value of leisure increase. Even so, the fall-back of the worker deteriorates, because the replacement rate is much lower. This implies that the gross wage falls, relative to marginal productivity (Figure 6). ${ }^{21}$

In two additional simulations we decompose the total effect of the reform into a replacement rate effect and a tax effect. ${ }^{22}$ In the first scenario, RRlow, only the replacement rate is reduced, while the tax rates are unchanged from the base case. In the second scenario, Tlow, tax rates are set at US levels. It appears from Figure 3 that in terms of the effects on labor supply, both measures contribute about equally to the increase in participation rates, though lowering the replacement rate has a slightly larger effect. The effect of both reforms on wages is different, however. Figure 6 shows that the lowering of the replacement rate is responsible for the larger part of the fall in gross wages. This neutrality of tax rates with respect to wage bargaining is a standard result from the literature (see e.g. Pissarides (1998)). However, we observe that here the tax rate does have an effect on wages for workers who have stopped searching. For these workers, the marginal value of leisure is no longer proportional to the return to search. As a result, a decrease in tax rates does not improve their fall-back position to the same degree as their return from work, so that the gross wage declines. ${ }^{23}$

A final analysis demonstrates that the outcomes are sensitive to the worker type. Instead of the average worker from the base case, we now consider a low productivity worker (a worker at $12 \%$ from the bottom of the productivity distribution). This worker has a productivity that is $73 \%$ lower on average than our modal worker. Because of minimum-wage related floors for social assistance rates, the replacement rate for this low-productivity worker rises to about $80 \%$ of his market wage. ${ }^{24}$ Figure 9 is in line with observed labor market behavior: low productivity workers supply less labor and retire early. The implicit search tax in Figure 10 attains a similar maximal level but at a much lower age, relative to the average worker.

\footnotetext{
${ }^{21}$ This is not a full equilibrium, because we neglect the effect of the fall in the gross wage on the creation of vacancies (see equation (9)). With more vacancies, unemployment duration falls, which improves the bargaining position of employees. This provides a counterforce to the decline of the replacement rate.

${ }^{22}$ Both measures are implemented in a balanced-budget framework, by means of lump sum taxes.

${ }^{23}$ The effect is somewhat obscured by the simultaneous increase in the period over which workes continue to search. This means that the search wedge starts to affect the wage outcome a few years later.

${ }^{24}$ Note also that the basic public pensions are independent of labor incomes.
} 
A transition to the US tax and benefit system (in particular the reduction of the replacement rate from $80 \%$ to $14 \%{ }^{25}$ ) affects the low-productivity worker more strongly than a model worker. After the policy reform, his labor supply becomes similar to that of the average worker. The welfare effect is also much stronger, with an equivalent variation of $44 \%$ of lifetime wealth.

\section{Conclusions}

This paper has investigated the age-dependency of participation and unemployment by integrating job search with intertemporal optimizing behavior of finitely-lived households. We show that labor supply can be classified into four consecutive stages: active job search; employed without active searching; voluntary quitting and full retirement. The representative agent case only considers the first stage, in which the return to job search equals the marginal value of leisure. However, for older workers this equality no longer holds, because the non-negativity constraint on search time becomes binding. As a result, search frictions and tax rates distort labor market decisions of older workers to a much larger extent than those of young workers.

Extending the standard Mortensen-Pissarides model with finite lives provides an explanation for several age-specific features of the labor market. First, the observed fall in participation rates of the elderly follows the decline in the return to search, caused by the approaching retirement. We point out that, in a life-cycle perspective, labor taxes and social insurance create a dynamic distortion, by affecting the return to search. We find that this distortion increases with age. This result provides an explanation of the observed fall of participation rates and retirement ages of elder workers as a result of the post-war increase of tax rates and replacement rates.

Second, higher search costs imply higher 'voluntary' unemployment. Voluntary unemployment is defined here as the extra amount that a household would be willing to work at the going wage rate if transaction costs were absent. The finding that unemployment is maximal a few years before the retirement age corresponds well with observations.

Third, the negotiated wage differs by age as the match surplus is age-specific. The (negative) gap between the wage and the marginal productivity rises with the search wedge, as this deteriorates the worker's fall-back position. For workers close to retirement, wages equal their productivity.

In view of the strong increase in the ageing costs, policies that stimulate labor participation of older workers are widely advocated. Our analysis indicates that older workers suffer from high implicit search taxes. Measures that decrease the replacement rates of the alternative exit routes are best suited for targeting these age-specific distortions.

The analysis is subject to three main limitations. First, the analysis is partial by leaving out effects on the equilibrium labor market flow rates. A general equilibrium analysis has to take into account changes in the distribution of the workers over ages as well as over types. Firms will post

\footnotetext{
${ }^{25}$ The replacement rate in the US is mostly independent of income.
} 
fewer vacancies if the proportion of job seekers with low job values rises. Second, the analysis is non-stochastic. Households self-insure against the unemployment risk by holding many small jobs. Thus there is no income risk and no precautionary saving. This limits the use of the model for welfare analysis. Examples of stochastic studies include Costain (1997) and Heer (1997). Third, the unemployment benefits are independent of the labor history as well as of the unemployment duration. In reality, the replacement rate falls strongly with the unemployment spell, at least for higher incomes (see OECD, 2002, Table 3.11). This implies that the model overstates the negative effects of unemployment insurance on labor market participation for higher incomes. 


\section{Appendix}

\section{A The model in discrete time}

For simulation purposes the model of section 2 is transferred to discrete time. Lifetime utility (14) is now written $a^{26}$ :

$$
\begin{aligned}
\Upsilon & =\frac{1}{1-1 / \gamma} \sum_{\tau=1}^{T} \frac{\Lambda(\tau)}{(1+\rho)^{\tau-1}} v(c(\tau), l(\tau))^{1-1 / \gamma} \\
v(\tau) & =\left[\theta^{1 / \sigma} c(\tau)^{1-1 / \sigma}+(1-\theta)^{1 / \sigma}\left(\theta_{l}(\tau) l(\tau)\right)^{1-1 / \sigma}\right]^{\sigma /(\sigma-1)}
\end{aligned}
$$

where $\sigma$ denotes the intratemporal substitution elasticity and $\Lambda(\tau)$ the survival probability. The budget constraint (12) is adjusted in the following ways. Assets receive an extra return $\mu(\tau)$, arising from the actuarially fair annuity. Proportional taxes are levied on capital income, labor income and consumption at the constant rates $\tau_{k}, \tau_{n}$ and $\tau_{c}$, respectively (i.e. $T^{\prime}=\tau_{n}$ ). Agespecific transfers $y(\tau)$ are added, in the form of public pensions paid from the age of 65 years (independent of the labor history). Unemployment benefits are a fraction of the individual net wage rate (i.e. $\pi_{u}=0$ ). The budget constraint (12) reduces to:

$$
\begin{aligned}
& (1-\mu(\tau)) a(\tau+1)=\left(1+r\left(1-\tau_{k}\right)\right) a(\tau)+\left(1-\tau_{n}\right) w(\tau) n(\tau)+ \\
& b(\tau)\left(1-\tau_{n}\right) w(\tau)(1-n(\tau))+y(\tau)-\left(1+\tau_{c}\right) c(\tau)
\end{aligned}
$$

The job accumulation equation (11) is:

$$
n(\tau)=\chi u(\tau)+(1-q(\tau)) n(\tau-1)
$$

with $n(0)=0$. Since the average unemployment duration $(1 / \chi)$ is less than one year, it is assumed that a person can find a job the same period that it searches. Finally, the restrictions on the time allocations must hold.

In the individual optimization problem the wage rate is exogenous. However, eq. (24) shows that the wage rate depends on the optimal decisions. Solving the model therefore requires finding the fixed point of (A.4), in which the marginal utilities are evaluated in the optimum ${ }^{27}$ :

$$
w(\tau)=\frac{1}{1-(1-\omega) b(\tau)}\left[\omega F_{N}(\tau) h(\tau)+(1-\omega) \frac{\left(1+\tau_{c}\right) v_{l}(\tau)}{\left(1-\tau_{n}\right) v_{c}(\tau)}\right]
$$

When the person does not supply labor $(n=0)$, the wage rate is not negotiated but set equal to productivity $F_{N} h$. In these cases, the wage only matters for the calculation of the unemployment benefits.

\footnotetext{
${ }^{26}$ The generation index $t_{0}$ is dropped in this section.

${ }^{27}$ In this section we are only interested in solutions of the individual optimisation problem. The analysis remains partial in the sense that the effect of the aggregate labor supply on marginal productivity $F_{N}$ is neglected. For the same reasons, balance on the government budget is not imposed.
} 


\section{B Calibration}

The simulations consider the adult life of a worker of modal productivity. Coefficient values are taken from the general equilibrium model IMAGE, calibrated for the Netherlands (see Broer, 1999). Parameters in the utility function are $\rho=0.02$ (rate of time preference), $\gamma=0.25$ (intertemporal elasticity of substitution), $\theta=0.71$ (consumption weight in utility flow), and $\sigma=0.73$ (intratemporal elasticity of substitution). For $\theta_{l}$, an exponential function is calibrated to match the observed participation rates, yielding $\theta_{l}(\tau)=1165.66 \exp (-0.13 \tau)$. The hump-shaped productivity index $h$ is calibrated from the observed wage profile. It starts at 0.4 at the age of 19 years; peaks at 1.5 at the age of 61 years and then starts to fall. The mortality rates are calculated from the mid-range demographic projection for the 1999 generation of Statistics Netherlands. The real interest rate is set at $5 \%$.

Carey and Tchilinguirian (2000) provide average effective tax rates over the period 199197, using a modified version of the Mendoza et al. (1994) methodology. The average gross replacement rate for 1999 is taken from OECD (2002). ${ }^{28}$ This rate $b$ is set at $0 \%$ for persons older than 65 years. Tax rates and the replacement rate for the benchmark case are given in column $N L$ in Table 1. Figure 2 gives the discrete counterpart of the tax wedge defined in (46). It shows that the wedge in the Netherlands is one of the largest in the OECD. We include only public pension transfer in pension income.

Regarding the labor market parameters, the matching rate $\chi$ is assumed to be 2 , implying an average unemployment duration $(1 / \chi)$ of half a year. The minimum separation rate $\bar{q}$ is set at $10 \%$ (In the Mortensen-Pissarides setting, these values would imply an unemployment rate of $\bar{q} /(\bar{q}+\chi)=4.8 \%$ in the steady state). Productivity $F_{N}(1)$ is chosen to replicate the average wage rate in the base year. It is assumed to grow at the rate of technical progress of $2 \%$. Finally, the bargaining power of the worker $\omega$ equals 0.5 .

Table 2: Labor supply elasticities of a modal worker

\begin{tabular}{ccccc}
\hline \hline age & productivity & income & replacement rate & tax wedge \\
\hline 20 & 0.017 & -0.217 & -0.097 & -0.273 \\
30 & 0.021 & -0.173 & -0.073 & -0.214 \\
40 & 0.062 & -0.247 & -0.103 & -0.308 \\
50 & 0.202 & -0.468 & -0.196 & -0.611 \\
60 & 0.000 & -1.134 & -0.460 & -0.558 \\
\hline \hline
\end{tabular}

\begin{tabular}{ll}
\hline Notes: & The shocks simulated to calculate the elasticities are \\
productivity: & increase of the productivity profile by $5 \%$ \\
income: & lump-sum transfer of 5\% of remaining lifetime income \\
replacement rate: & see scenario Rlow (including compensating lump-sum transfers) \\
tax wedge: & see scenario Tlow (including compensating lump-sum transfers)
\end{tabular}

Table 2 presents a number of labor supply elasticities of the calibrated model. The (uncompensated) productivity elasticity of labor supply is around zero for young workers, but increases substantially for middle-aged workers. The elasticity drops to zero for workers who are no longer

\footnotetext{
${ }^{28}$ This summary measure is calculated as the unweighted average of 18 gross unemployment benefit replacement rates for three household types, three durations and two earnings levels.
} 
actively engaged in job search. ${ }^{29}$ The average supply elasticity is consistent with the econometric evidence of reduced-form labor supply equations (see Pencavel (1986)). The income effect of labor supply is about -0.3 , which is in the middle of the estimates surveyed by Pencavel. It too increases with age. ${ }^{30}$ The effect of the replacement rate on labor supply is rather close to the estimates presented by Broer et al. (2000), whereas the elasticities of the tax wedge are a bit larger, but still in the same order of magnitude.

\section{Proofs}

\section{Proof of Proposition 1}

Based on the complementary slackness conditions, $2^{4}=16$ different multiplier combinations may be distinguished. Most of these combinations may be excluded beforehand. First, $\lambda_{l}>0$ may be excluded on the argument that this would result in an unbounded marginal utility of leisure for $\gamma<\infty$. Second, the complementary slackness condition (18c) implies that if $q(t)>\bar{q}(t)$, then $\lambda_{q}(t)=0$. Suppose $\lambda_{q}(t)=0$, then from (18b), $p_{n}(t)=0$ as well. This says that if a household is voluntarily quitting jobs, ${ }^{31}$ the marginal asset value of a job must be zero. If a household chooses to do this over an interval $\left[t_{1}, t_{2}\right]$, then for $t \in\left(t_{1}, t_{2}\right), \dot{p}_{n}=0$. It follows from (16) that for $t \in\left(t_{1}, t_{2}\right)$ and $n(t)>0,\left(1+\tau_{c}\right) \frac{v_{l}}{v_{c}}=w(t)\left[1-b-T^{\prime}\right]$ and (18a) then leads to $\lambda_{u}(t)=w(t)\left(1-b-T^{\prime}\right)-$ $\pi_{u}(t)$. Hence, as long as the effective unemployment replacement rate $\pi_{u} / w\left(1-b-T^{\prime}\right)$ is below unity, $\lambda_{q}(t)=0 \wedge \lambda_{n}(t)=0 \Rightarrow \lambda_{u}(t)>0$ for $t \in\left(t_{1}, t_{2}\right) .{ }^{32}$ If on the other hand $\lambda_{n}(t)>0, n(t)=0$ and from (18b) $\lambda_{q}(t)=0$. Therefore we can also disregard all cases with $\lambda_{n}(t)>0 \wedge \lambda_{q}(t)>0$ (with zero jobs, quitting carries no costs).

The number of multipliers combinations may therefore be reduced to four, Case $1\left(\lambda_{u}=\right.$ $0, \lambda_{q}>0, \lambda_{n}=0$ and $\left.u>0, q=\bar{q}, n>0\right)$, Case $2\left(\lambda_{u}>0, \lambda_{q}>0, \lambda_{n}=0\right.$ and $\left.u=0, q=\bar{q}, n>0\right)$, Case $3\left(\lambda_{u}>0, \lambda_{q}=0, \lambda_{n}=0\right.$ and $\left.u=0, q>\bar{q}, n>0\right)$, and Case $4\left(\lambda_{u}>0, \lambda_{q}=0, \lambda_{n}>0\right.$ and $u=0, q \geq \bar{q}, n=0){ }^{33}$

\section{References}

Atkinson, A.B. (1999), The Economic Consequences of Rolling back the Welfare State, MIT Press.

Bhattacharya, J., C.B. Mulligan, and R.R. Reed (2001), "Labor Market Search and Optimal Retirement Policy,” NBER Working Paper 8591.

\footnotetext{
${ }^{29}$ The elasticity has been computed as the effect of a $5 \%$ permanent increase in productivity, starting from the relevant age. Conceptually, this productivity elasticity comes closest to a wage elasticity of labor supply. Note that a sufficiently large increase in productivity would create an incentive for these workers to resume job search. On the other hand, a sufficiently large fall in productivity induces quitting.

${ }^{30}$ The remarks in Footnote 29 also apply to income effects. Small income changes do not affect labor supply of nonsearching households. However, a (large) increase of $5 \%$ of remaining lifetime income reduces the job value sufficiently to induce voluntary quits.

31 "Quitting" in this context may also be interpreted as a reduction in working time.

${ }^{32}$ That is, a household is not involuntarily unemployed at the same time that it is quitting. However, in the extreme case that the replacement rate is above unity, the household continues to search while quitting, to collect the unemployment benefit.

${ }^{33}$ with $\lambda_{l}=0$ in all four cases.
} 
Blau, D.M. (1994), “Labor Force Dynamics of Older Men,” Econometrica, 62, 117-156.

Blundell, R. and T. MaCurdy (1999), "Labor Supply: A Review of Alternative Approaches," Chapter 27 in O. Ashenfelter and D. Card (eds.), Handbook of Labor Economics, Volume $3 A$, Elsevier.

Blundell, R., C. Meghir, and P. Neves, (1993), "Labour Supply and Intertemporal Substitution," Journal of Econometrics, 59, 137-160.

Bound, J. and R.V. Burkhauser (1999), "Economic Analysis of Transfer Programs Targeted on People with Disabilities," Chapter 51 in O. Ashenfelter and D. Card (eds.), Handbook of Labor Economics, Volume 3C, Elsevier.

Broer, D.P. (1999), "Growth and Welfare Distribution in an Ageing Society: an Applied General Equilibrium Analysis for the Netherlands," OCFEB Research Memorandum 9908, Erasmus University (downloadable from http://www.few.eur.nl/few/research/pubs/ocfeb/documents/rm9908.pdf).

Broer, D.P., D.A.G. Draper and F.H. Huizinga (2000), "The Equilibrium Rate of Unemployment in the Netherlands," De Economist, 148, 345-371.

Browning, M., L.P. Hansen and J.J. Heckman (1999), "Micro Data and General Equilibrium Models," Chapter 8 in J.B. Taylor and M. Woodford (eds.), Handbook of Macroeconomics, North-Holland.

Card, D. (1994), "Intertemporal Labor Supply," in C.A. Sims (ed.), Advances in Econometrics: Sixth World Congress, Volume II, Cambridge.

Carey, D. and H. Tchilinguirian (2000), "Average effective tax rates on capital, labour and consumption,” OECD Economics Department Working Paper No. 258.

Costain, J.S. (1997), "Unemployment Insurance with Endogenous Search Intensity and Precautionary Saving," Economics Working Papers 243, Department of Economics and Business, Universitat Pompeu Fabra.

Engen, E.M. and J. Gruber (2001), "Unemployment Insurance and Precautionary Saving," Journal of Monetary Economics, 47, 545-579.

Gruber, J. and D. Wise (1997), "Social Security Programs and Retirement Around the World," NBER Working Paper 6134.

Haveman, R.H. and B.L. Wolfe (1984), Disability Transfers and Early Retirement: A Causal Relationship," Journal of Public Economics, 31, 131-161.

Heer, B. (1997), "Unemployment Insurance versus Welfare Payments: a Dynamic CGE Analysis of Employment and Welfare Effects," Public Finance, 52, 367-393.

Kapteyn, A. and K. de Vos (1998), "Social Security and Labor-Force Participation in the Netherlands," American Economic Review, 88, May, 164-67.

Lazear, E. (1979), “Why is There Mandatory Retirement?" Journal of Political Economy, 87, 1261-1284. 
Lumsdaine, R.L. and O.S. Mitchell (1999), "New Developments in the Economic Analysis of Retirement," Chapter 49 in O. Ashenfelter and D. Card (eds.), Handbook of Labor Economics, Volume 3C, Elsevier.

Mankiw, N.G., J.J. Rotemberg, and L.H. Summers (1985), "Intertemporal Substitution in Macroeconomics," Quarterly Journal of Economics, 100, 225-251.

Mendoza, E.G.; A. Razin and L.L. Tesar (1994), "Effective Tax Rates in Macroeconomics: Cross-Country Estimates of Tax Rates on Factor Incomes and Consumption," Journal of Monetary Economics, 34(3), 297-323.

Merz, M. (1995), "Search in the Labor Market and the Real Business Cycle," Journal of Monetary Economics, 36, 269-300.

Mortensen, D.T. and C.A. Pissarides (1999a), "New Developments in Models of Search in the Labor Market," Chapter 39 in O. Ashenfelter and D. Card (eds.), Handbook of Labor Economics, Volume 3B, Elsevier.

Mortensen, D.T. and C.A. Pissarides, (1999b), "Unemployment Responses to 'Skill-Biased' Technology Shocks: The Role of Labour Market Policy," Economic Journal, 109, 242-265.

Mulligan, C.B. (1998), "Substitution over Time: Another Look at Life Cycle Labor Supply," NBER Working Paper No. 6585.

OECD (2002), Benefits and Wages, Paris.

Pencavel, J. (1986), “Labor Supply of Men: a Survey,” in O. Ashenfelter and R. Layard (eds.), Handbook of Labor Economics, 3-102.

Pissarides, C.A. (1990), Equilibrium Unemployment Theory, Blackwell.

Pissarides, C.A. (1998), "The Impact of Employment tax Cuts on Unemployment and Wages; The Role of Unemployment Benefits and Tax Structure," European Economic Review, 42, 155-183.

Rein, M. and K. Jacobs (1993), "Ageing and Employment Trends: a Comparative Analysis for OECD Countries," Chapter 3 in P. Johnson and K.F. Zimmerman (eds.), Labour Markets in an Ageing Europe, Cambridge.

Shi, S. and Q. Wen (1997), "Labor Market Search and Capital Accumulation: Some Analytical Results," Journal of Economic Dynamics and Control, 21, 1747-1776.

Shi, S. and Q. Wen, (1999), "Labor market search and the dynamic effects of taxes and subsidies," Journal of Monetary Economics, 43, 457-495.

Shimer, R. and L. Smith (2001), "Matching, Search, and Heterogeneity," Advances in Macroeconomics, $\mathbf{1}$, number 5 .

Weiss, Y. (1986), "The Determinants of Life Cycle Earnings: A Survey," Chapter 11 in O.Ashenfelter and R. Layard (eds.), Handbook of Labor Economics, vol. I, North-Holland

Yaari, M.E. (1965), "Uncertain Lifetime, Life Insurance, and the Theory of the Consumer," The Review of Economic Studies, 32, 137-150. 


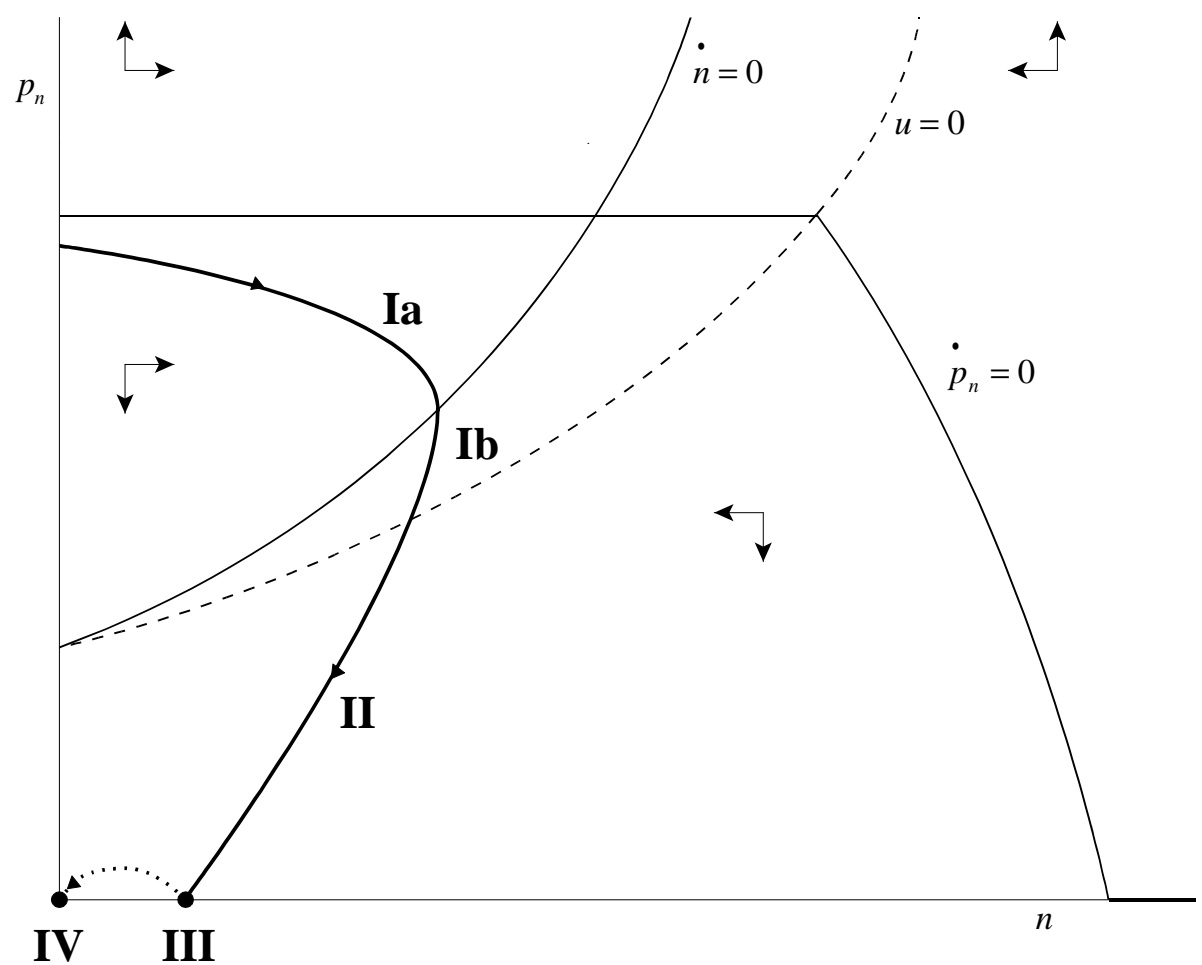

Figure 1: Labor supply and job value over the life cycle

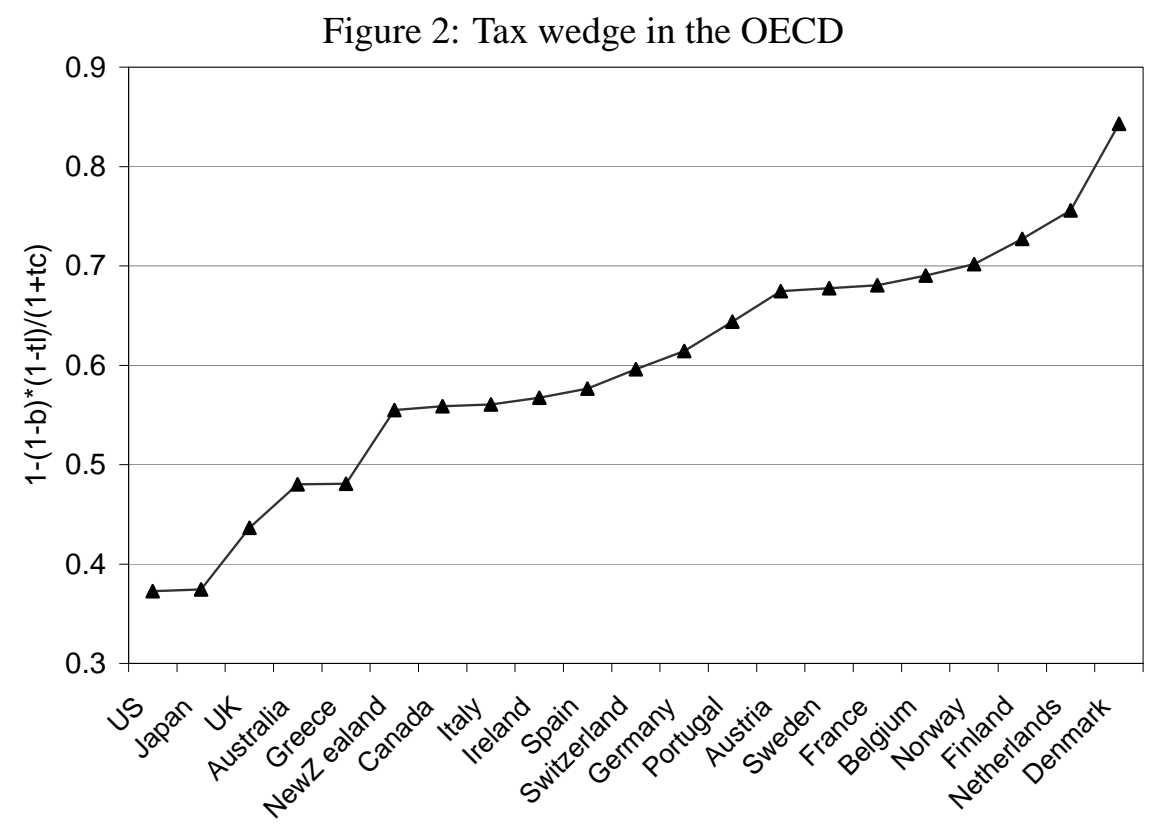




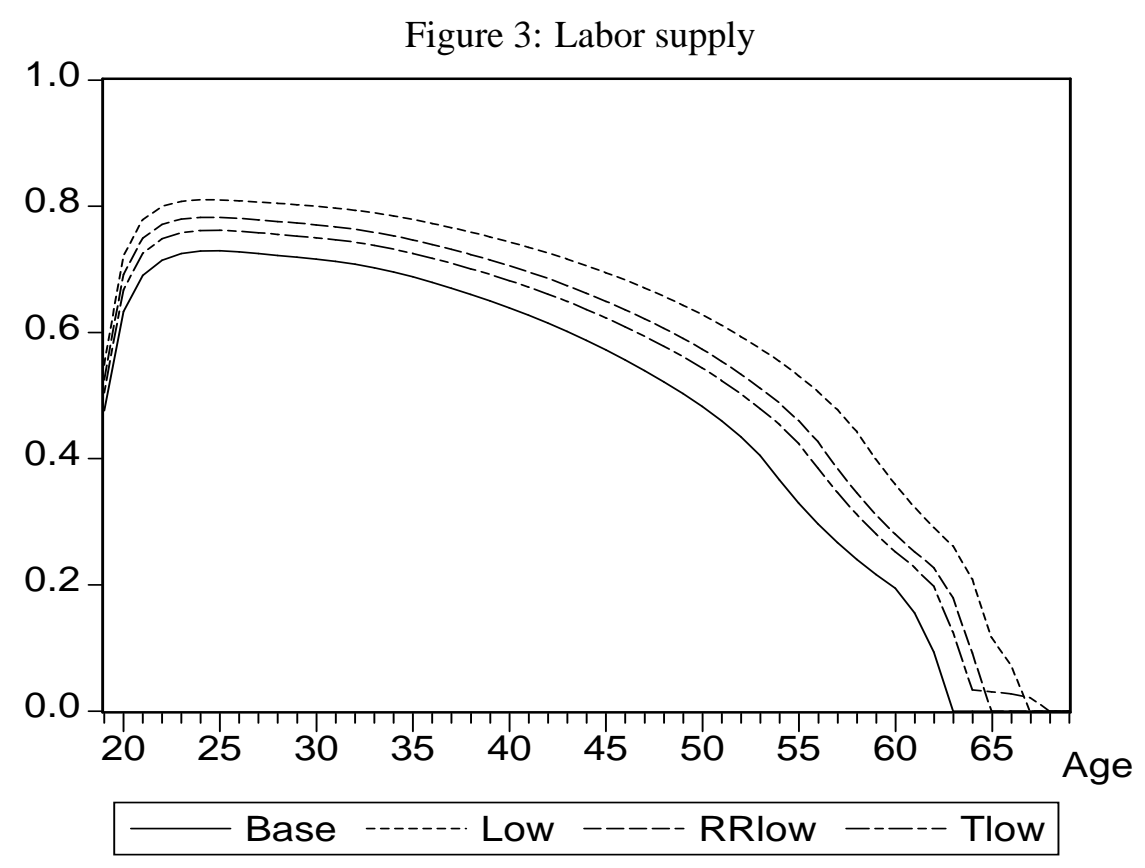

Figure 4: Search unemployment

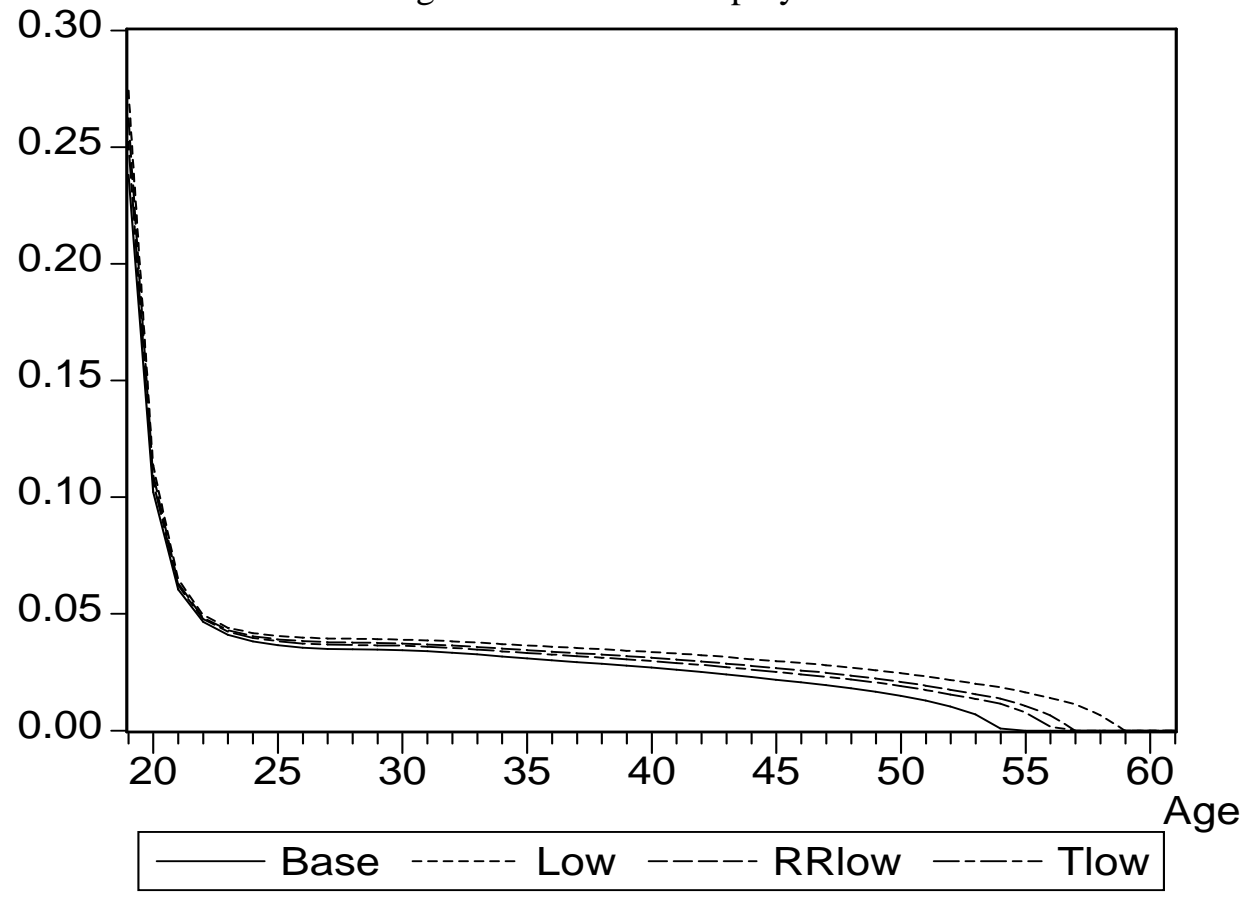




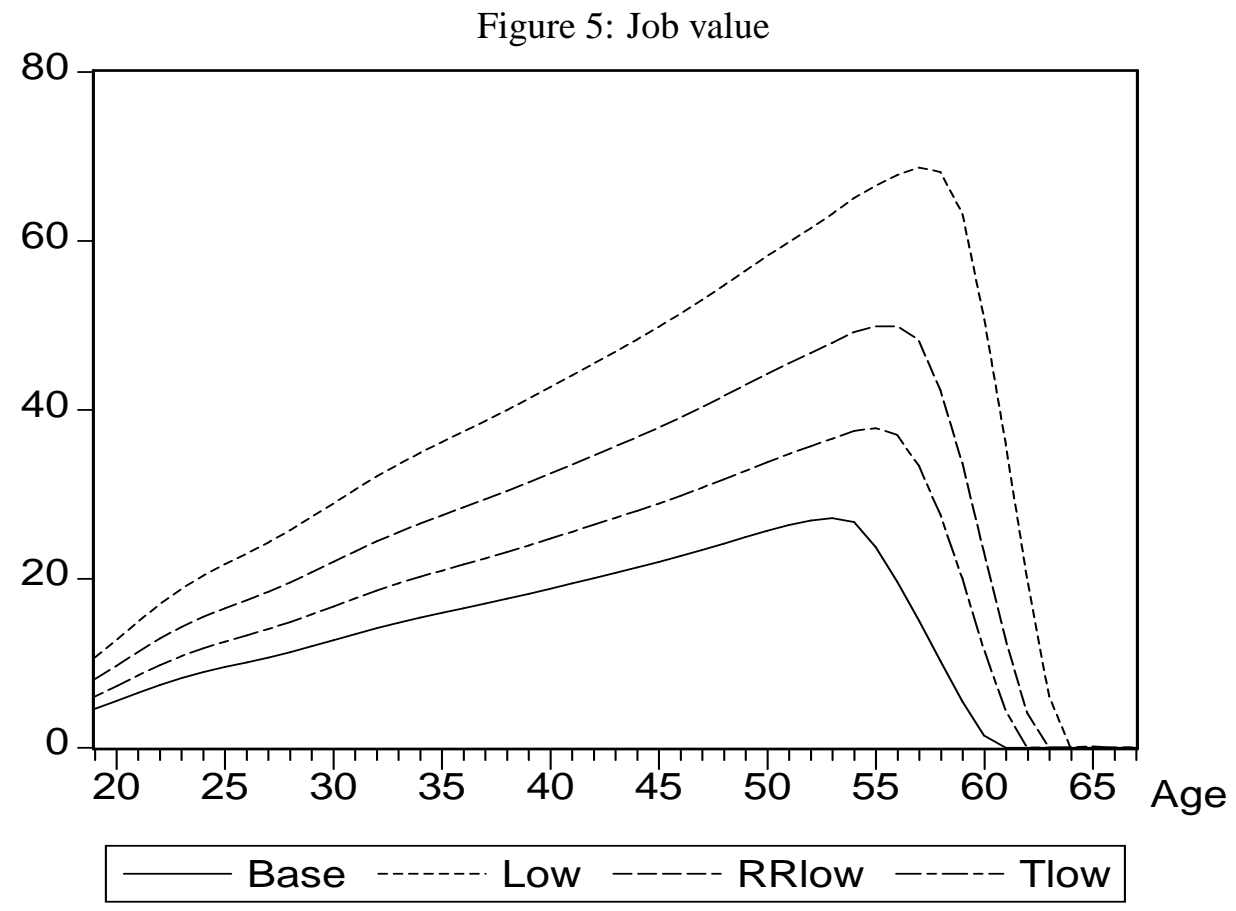

Figure 6: Ratio MP/Gross Wage

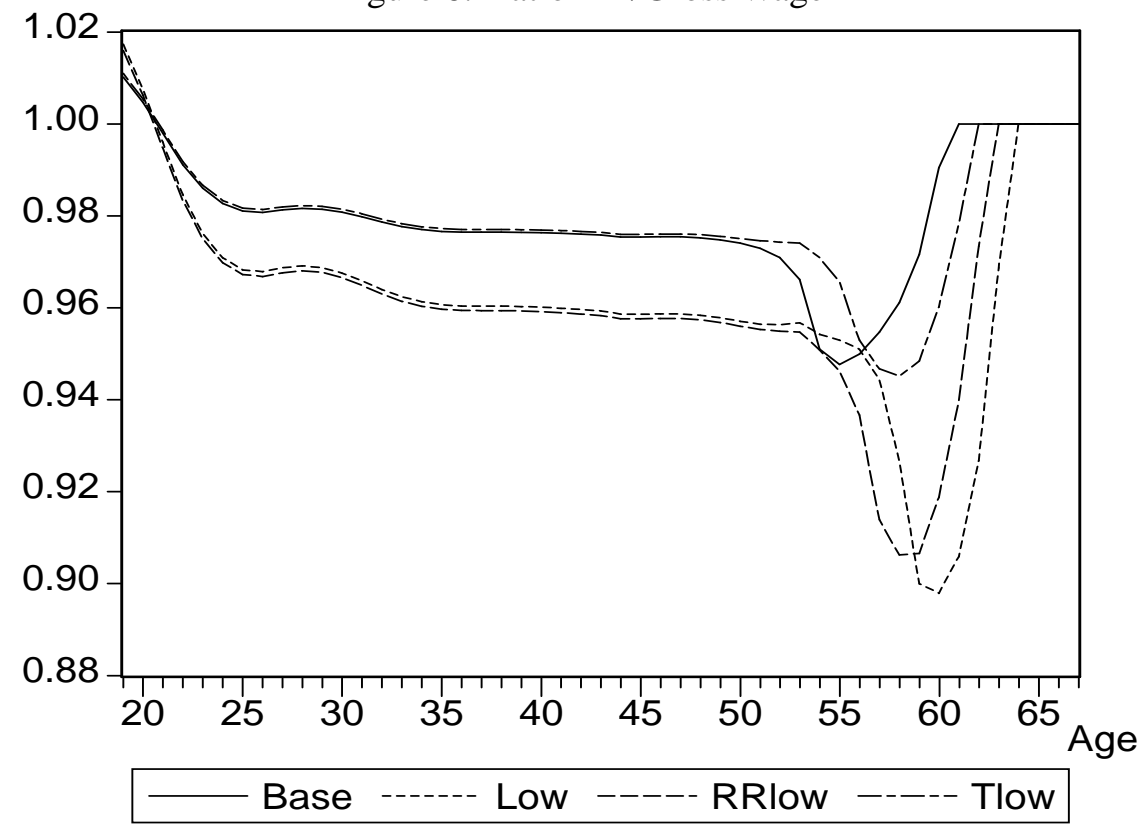



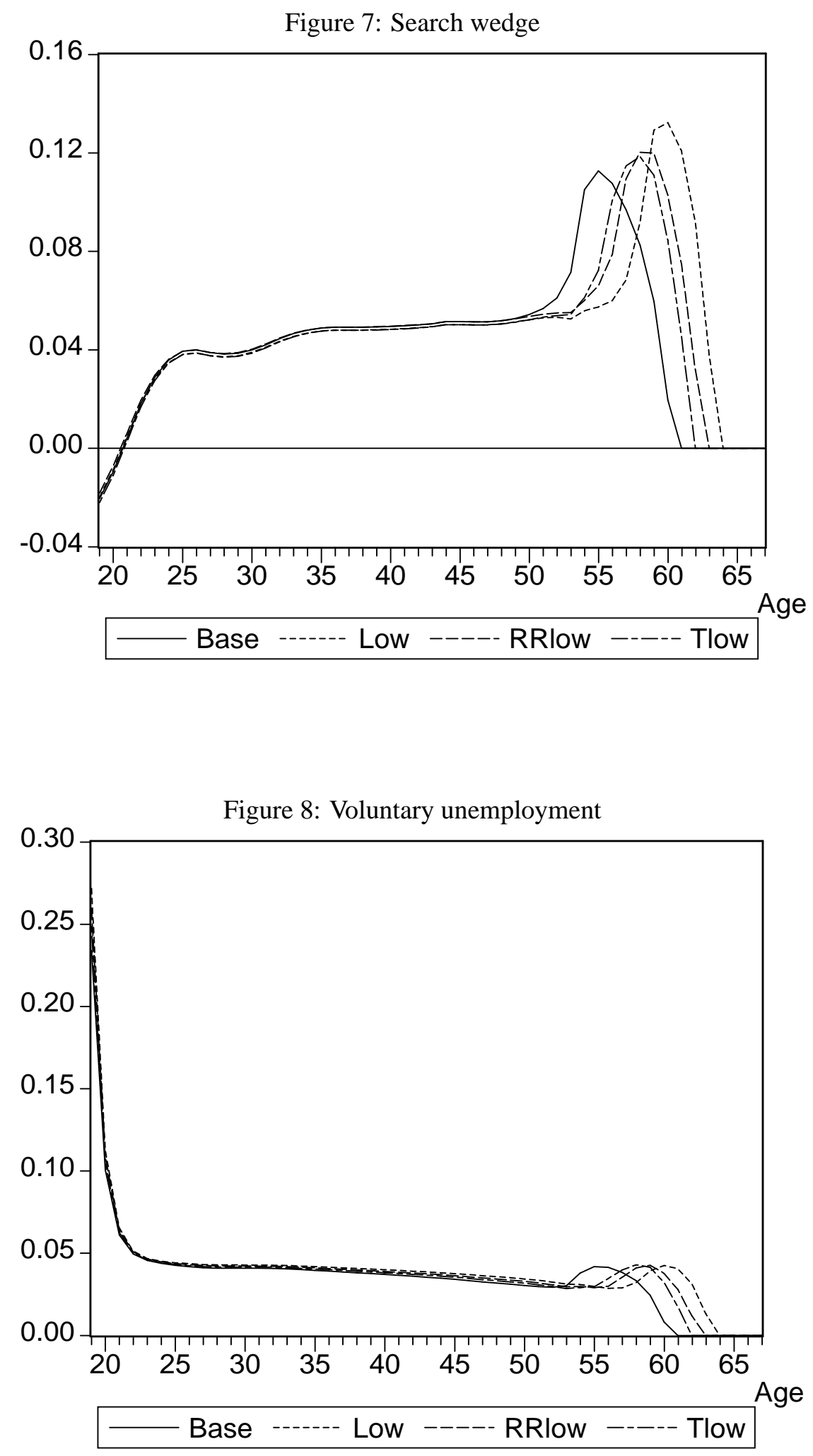

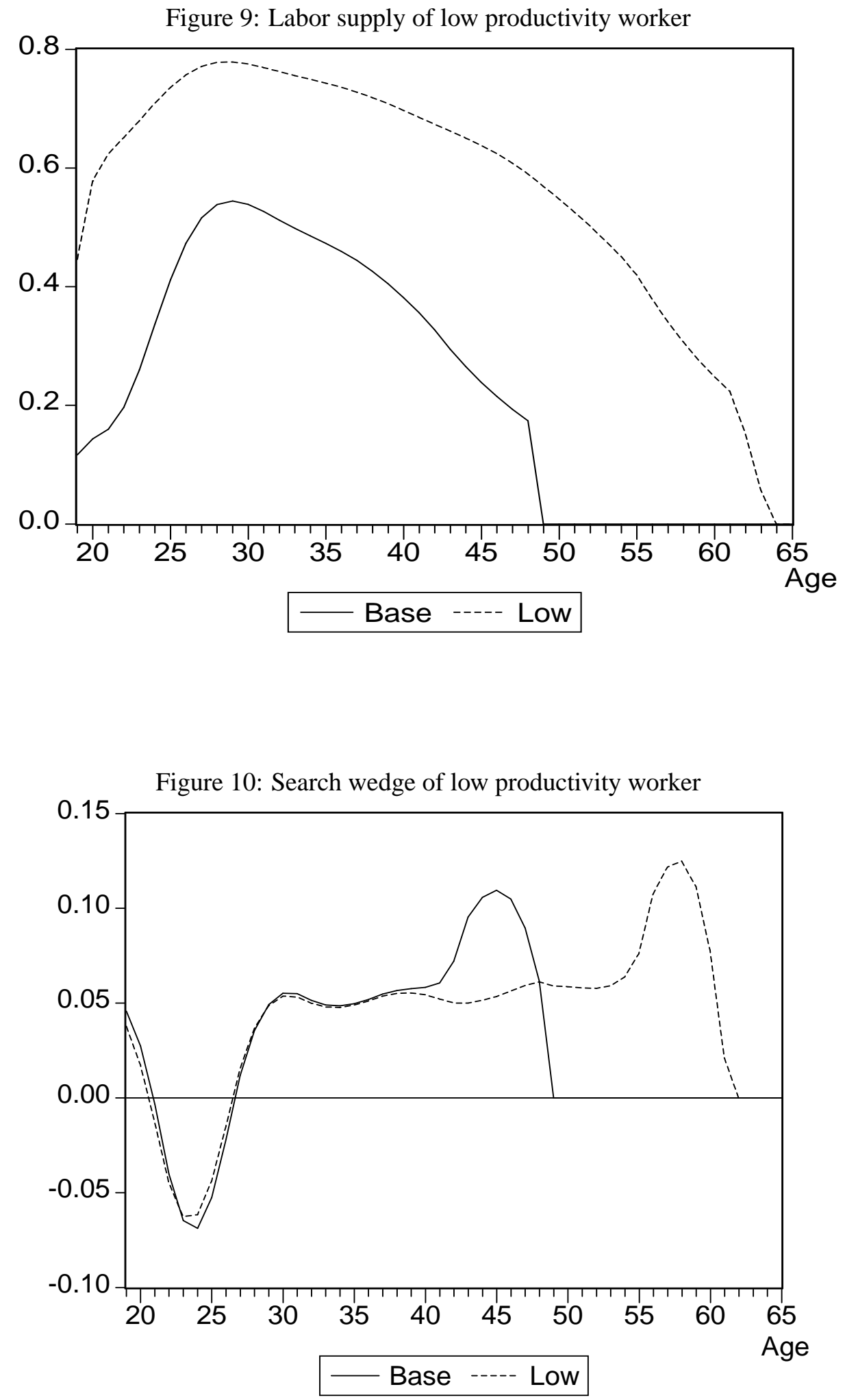